\title{
Evaluation of forward-modelled attenuated backscatter using an urban ceilometer network in London under clear-sky conditions
}

Article

Accepted Version

Creative Commons: Attribution-Noncommercial-No Derivative Works 4.0

Warren, E., Charlton-Perez, C., Kotthaus, S., Lean, H., Ballard, S., Hopkin, E. and Grimmond, S. (2018) Evaluation of forwardmodelled attenuated backscatter using an urban ceilometer network in London under clear-sky conditions. Atmospheric Environment, 191. pp. 532-547. ISSN 1352-2310 doi: https://doi.org/10.1016/j.atmosenv.2018.04.045 Available at https://centaur.reading.ac.uk/76924/

It is advisable to refer to the publisher's version if you intend to cite from the work. See Guidance on citing.

To link to this article DOI: http://dx.doi.org/10.1016/j.atmosenv.2018.04.045

Publisher: Elsevier

All outputs in CentAUR are protected by Intellectual Property Rights law, including copyright law. Copyright and IPR is retained by the creators or other copyright holders. Terms and conditions for use of this material are defined in the End User Agreement. 


\section{www.reading.ac.uk/centaur}

\section{CentAUR}

Central Archive at the University of Reading

Reading's research outputs online 


\title{
Evaluation of forward-modelled attenuated backscatter using an urban ceilometer network in London under clear-sky
} conditions

\author{
Elliott Warren ${ }^{1 *}$, Cristina Charlton-Perez ${ }^{2}$, Simone Kotthaus $^{1,3}$, Humphrey Lean ${ }^{2}$, Sue Ballard $^{2}$, Emma Hopkin $^{1}$, Sue Grimmond $^{1 *}$ \\ ${ }^{1}$ Department of Meteorology, University of Reading, UK \\ ${ }^{2}$ Met Office@Reading, UK \\ ${ }^{3}$ Institut Pierre Simon Laplace (IPSL), France
}

*Corresponding authors: e.l.warren@pgr.reading.ac.uk, c.s.grimmond@ reading.ac.uk

\begin{abstract}
Numerical weather prediction (NWP) of urban aerosols is increasingly sophisticated and accurate. In the absence of large particles (e.g. rain, cloud droplets), information on atmospheric aerosols can be obtained from single wavelength automatic lidars and ceilometers (ALC) that measure profiles of attenuated backscatter $\left(\beta_{o}\right)$. To assess the suitability of ALC profile observations for forecast evaluation and data assimilation, a forward operator is required to convert model variables into the measured quantity. Here, an aerosol forward operator (aerFO) is developed and tested with Met Office NWP data (UKV $1.5 \mathrm{~km}$ ) to obtain synthetic attenuated backscatter profiles $\left(\beta_{m}\right)$. aerFO requires as input the profiles of bulk aerosol mass mixing ratio and relative humidity to compute $\beta_{m}$, plus air temperature and pressure to calculate the effect of water vapour absorption. Bulk aerosol characteristics (e.g. mean radius and number concentration) are used to estimate optical properties. ALC profile observations in London are used to assess $\beta_{m}$. A wavelength-dependent extinction enhancement factor accounts for the change in optical properties due to aerosol swelling. Sensitivity studies show the aerFO unattenuated backscatter is very sensitive to the aerosol mass and relative humidity above $\sim 60-80 \%$. The extinction efficiency is sensitive to the choice of aerosol constituents and to ALC wavelength.Given aerosol is a tracer for boundary layer dynamics, application of the aerFO has proven very useful to evaluate the performance of urban surface parameterisation schemes and their ability to drive growth of the mixing layer. Implications of changing the urban surface scheme within the UKV is explored using two spring cases. For the original scheme, morning $\beta_{m}$ is too high probably because of delayed vertical mixing. The new scheme reduced this persistence of high morning $\beta_{m}$, demonstrating the importance of surface heating processes. Analysis of profiles at five sites on 12 clear-sky days shows a positive, statistically significant relation between the differences of modelled and measured near-surface attenuated backscatter $\left[\beta_{m}-\beta_{o}\right]$ and near-surface aerosol mass. This suggests errors in near-surface attenuated backscatter can be attributed to errors in the amount of aerosol estimated by the NWP scheme. Correlation increases when cases of high relative humidity in the NWP model are excluded. Given the impact on aerosol optical properties demonstrated, results suggest the use of a fixed, bulk aerosol for urban areas in the UKV should be revisited and the lidar ratio should be constrained. As quality of the observed attenuated backscatter is demonstrated to be critical for performing model evaluation, careful sensor operation and data processing is vital to avoid false conclusions to be drawn about model performance.
\end{abstract}

Keywords: aerosols; lidar forward operator; numerical weather prediction; ALC; urban land surface models; data assimilation

\section{Introduction}

Urban aerosols impact health (Atkinson et al., 2014; Chen et al., 2015; Elliot et al., 2016; Xing et al., 2016; Yin et al., 2017), visibility (Sabbagh-Kupelwieser et al., 2010; Stull, 1988) and local radiation budgets (Boucher et al., 2013; Haywood and Boucher, 2000; Marley and Gaffney, 2006) and with a high density of people in urban areas, many may be impacted. Most countries, such as EU member states (EEA, 2015), have legal maxima set for several air quality constituents. Identifying when behavioural changes are needed (e.g. reduction of car usage) in advance of critical exceedances requires improved understanding, and accurate prediction of, aerosol concentrations in urban areas.

Aerosol concentration and transport can be predicted with atmospheric chemistry models that are one- or two-way coupled to a numerical weather prediction (NWP) model (Benedetti et al., 2009; Grell et al., 2004; Appendix 1). As including an atmospheric chemistry model is significantly more computationally expensive than standalone NWP (Clark et al., 2008), this reduces their operational utility. However, NWP resolution has increased and aerosols have been included more explicitly (Benedetti et al., 2009; Lu et al., 2016). Some contain information on various aerosol species, e.g. the AQUM configuration of the Met Office (MO) Unified Model (Savage et al., 2013) and the Integrated Forecasting System (IFS) at the European Centre for Medium-Range Weather Forecasts (ECMWF). AQUM and IFS include mass mixing ratios for different aerosol species such as salt, dust, organic carbon, black carbon, sulphate and nitrate for use in radiation parameterisations (Benedetti et al., 2009; Morcrette et al., 2008) which makes them more 
computationally expensive. Another example is the MO operational variable resolution (UKV) NWP model (1.5 km inner, $4 \mathrm{~km}$ outer domain) (Tang et al. 2013) that has an aerosol proxy (Clark et al., 2008) with a single mass mixing ratio $\left(m_{M U R K}, \mathrm{~kg} \mathrm{~kg}^{-1}\right)$ derived from emission inventories (Neal, 2016) (Appendix 1). This aerosol scheme (called MURK) is designed to be computationally inexpensive for use in a visibility parameterisation and data assimilation scheme (Claxton, 2013).

Vertical profiles of atmospheric aerosols are monitored with remote sensing instruments on satellites (Chudnovsky et al., 2013; Goto et al., 2011; Jose et al., 2016; You et al., 2016), aircrafts (Li et al., 2015), and the ground (Wiegner et al., 2014). While satellite observations provide extensive spatial coverage, their temporal resolution is limited. When the near surface atmosphere is of interest, ground-based profilers are useful as the signal is less likely to be saturated by clouds. Automatic lidars and ceilometers (ALC) are single-wavelength lidars, designed to provide cloud base height (CBH; Emeis, 2011), using the strong scattering properties of cloud droplets at ALC wavelengths (Martucci et al., 2010; Sharma et al., 2015; Willén et al., 2005). With increased sensitivity, it is possible to derive information about smaller aerosols (Wiegner et al., 2014). The capability to measure attenuated backscatter $\left(\beta_{o}\right)$ profiles is being exploited, for example, to track volcanic ash clouds (Flentje et al., 2010a), or Saharan dust (Jin et al., 2015), in the expanding ALC networks (Flentje et al., 2010b; Pappalardo et al., 2014; Sugimoto et al., 2008). Urban aerosol characteristics such as $P M_{2.5}$ and PM10 concentrations (Münkel et al., 2007; You et al., 2016), aerosol layers (McKendry et al., 2009; Zéphoris et al., 2005) and mixedlayer height (Poltera et al., 2017; Schafer et al., 2011; Schäfer et al., 2012; Wagner and Schäfer, 2015) have previously been explored using ALC attenuated backscatter measurements.

Data assimilation (DA) in NWP has used CBH data (Francis, 2012; Janisková et al., 2002; Lopez, 2002), and more recently attenuated backscatter profiles (Benedetti and Dabas, 2016; Charlton-Perez et al., 2016; Janisková et al., 2010; Janisková and Stiller, 2010). As specific aerosol properties such as radius and number concentration distributions are not observed by ALC, a forward operator (FO) is required to enable quantitative comparison to modelled values. Several FOs for atmospheric-chemistry and NWP model evaluation exist. For example, the Geisinger et al. (2017) FO estimates attenuated backscatter $\left(\beta_{m}\right)$ from volcanic ash clouds in the free troposphere using COSMO-ART over Germany and ALC data but omits the effect of backscatter from boundary layer aerosols. Another FO estimates backscatter from dust and sea salt with the ECMWF IFS using CALIOP data from the CALIPSO satellite (Table 1 in Morcrette et al., 2009). The Chan et al. (2016) FO for Lufft CHM15K ALC measurements estimates attenuated backscatter has a prognostic mass mixing ratio of different aerosol species from NWP, utilising either Mie or T-matrix calculation with fixed size distributions and growth factors for a set number of species. The Charlton-Perez et al. (2015) FO to estimate vertical profiles of $\beta_{m}$ accounts for the effects of aerosols (using MURK; Clark et al. 2008), liquid cloud and rain. Initial testing at rural sites suggests the FO produced realistic $\beta_{m}$ compared to $\beta_{o}$ observed with Vaisala CL31 (Charlton-Perez et al., 2015, 2016). However, this FO is effectively wavelength-independent, with a fixed scattering efficiency $\left(Q_{e x t}=2\right)$, a value typically not suitable for aerosols. Although this FO only requires the total bulk mass mixing ratio as aerosol input, it does not speciate the aerosol, so that physical growth and scattering properties are assumed invariant between particles. The latter is a critical assumption given these properties vary significantly between different aerosol species (Seinfeld and Pandis, 2016).

The objectives of this paper are to: (i) demonstrate a technique to evaluate the aerosol mass mixing ratio in NWP using ALC measurements, and (ii) comment on the potential application of ALC-measured attenuated backscatter profiles in DA. To do so, the aerosol component of the Charlton-Perez et al. (2015) FO is extended (hereafter aerFO, section 2) to include aerosol speciation and wavelength dependency. A sensitivity study is undertaken to assess the impact of several assumptions in the aerFO (section 3). Subsequently, aerFO is used to evaluate $m_{M U R K}$ and relative humidity $(R H)$ from the UKV in a city (London, UK) based on a comparison of two spring day cases (section 4) and a composite of 11 cloud-free days (section 5).

\section{The cloud-free aerosol Forward Operator (aerFO)}

The aerosol forward operator (aerFO) accounts for aerosols only. Therefore, it is suitable for use in sub-saturated, cloud-free conditions, in the absence of hydrometeors. To compute $\beta_{m}$ (Figure 1) the main inputs are vertical profiles of a bulk aerosol mass mixing ratio (such as $m_{M U R K}$ ) and $R H$. Secondary inputs of specific water vapour (q), air temperature $\left(\mathrm{T}_{\text {air }}\right)$ and air pressure (p) are used to correct for water vapour absorption.

In aerFO the bulk aerosol characteristics (i.e. mean dry particle radius $r_{m d}$ and number concentration $N$ ) are determined first (part 1 in Figure 1). The mean dry particle radius is a function of the standard mass concentration $\left[m_{o}, \mathrm{~kg} \mathrm{~kg}^{-1}\right]$ (Claxton, 2013), the standard aerosol particle radius $r_{o}$ and a scaling factor $p$ (Figure 1). A similar scaling is applied to estimate $N$, as a function of the background number concentration $\left(N_{0}\right)$. When $p=1 / 6$, both $N$ and $r_{m d}$ increase as $m$ increases (Clark et al., 2008; Haywood et al., 2008). The aerFO aims to represent the accumulation mode of the aerosol distribution using $N_{0}$ and $r_{0}$, as this contains a large proportion of the 
Warren E, C Charlton-Perez, S Kotthaus, H Lean, S Ballard, E Hopkin, S Grimmond 2018 Evaluation of forward-modelled attenuated backscatter using an urban ceilometer network in London under clear-sky conditions Atmospheric Environment https://doi.org/10.1016/j.atmosenv.2018.04.045

mass (Seinfeld and Pandis, 2016). Here, the accumulation range is defined as 0.04-0.7 $\mu \mathrm{m}$ as interpreted from aerosol distributions taken during the winter intensive observation period of the ClearfLo (Bohnenstengel et al., 2015b) and REPARTEE II (Harrison et al., 2012) campaigns. Default values for aerFO parameters are shown in Table 1.

Using $r_{m d}, R H$ and the assumed aerosol constituents, $Q_{e x t}$ is calculated (part 2 in Figure 1) as a function of ALC wavelength (section 3.1). This includes using a $R H$-dependent extinction enhancement factor $\left(f_{\text {ext }, r h}\right)$ to represent the change in optical properties due to hygroscopic growth of aerosol. The particle extinction coefficient $\left(\sigma_{e x t, a e r}\right)$ is then calculated from $Q_{e x t}$ (part 3 in Figure 1). Because water vapour strongly attenuates radiation at certain wavelengths, the water vapour extinction coefficient is calculated explicitly $\left(\sigma_{e x t, w v}\right)$ and used with $\sigma_{e x t, a e r}$ in the determination of the total extinction coefficient ( $\left.\sigma_{e x t}\right)$ (part 3 in Figure 1). When integrated over the atmospheric column, from ground $(z=0 \mathrm{~m})$ to a model level height $\left(z_{i}\right), \sigma_{e x t}$ provides the aerosol optical depth $(\tau)$ up to height $z_{i}$. Aerosol optical depth is then used to obtain the two-way transmission, $T$ (part 4 in Figure 1). The backscatter $\left(\beta_{m \text {, unatt }}\right.$ ) is derived using $\sigma_{e x t, a e r}$ and an assumed lidar ratio ( $S$, i.e. extinction-to-backscatter ratio). Currently, the extinction and backscatter of air molecules is not considered in the aerFO.

Assuming aerosol is the only significant source of backscatter, a lidar ratio $S$ for continental aerosol is applied (Doherty et al., 1999). However, $S$ varies considerably in space and time as it is strongly dependent on particle size, shape and refractive index (Müller et al., 2007); from $20 \mathrm{sr}$ (marine) to over $100 \mathrm{sr}$ (volcanic aerosols) (Ansmann et al., 2010; Boyouk et al., 2011; Dawson et al., 2015;

Geisinger et al., 2017; Povey et al., 2014; Wang et al., 2016). Using the fixed lidar ratio (Table 1) will introduce increased uncertainty as continental aerosol becomes less likely (e.g. during sea breezes), but without known values, a fixed $S$ is used in this study. Finally, attenuated backscatter $\left(\beta_{m}\right)$ is the product of $T$ and $\beta_{m \text {,unatt }}$ (part 4 in Figure 1).

Table 1: Parameters required by the aerosol forward operator (aerFO) and their default values. * Calculated from ClearfLo Winter intensive observation campaign data at North Kensington, London (10 Jan 2012 - 8 Feb 2012) using the DMPS and TSI APS (Bohnenstengel et al., 2015a).

\begin{tabular}{|l|l|l|l|}
\hline Symbol & Parameter & Default value & Value source \\
\hline$S$ & Lidar ratio & $60 \mathrm{sr}$ & Doherty et al. (1999) \\
\hline$\eta$ & Proportionality constant & 0.75 & Clark et al. (2008) \\
\hline$r_{0}$ & Standard mass particle radius & $1.1 \times 10^{-7} \mathrm{~m}$ & Haywood et al. (2008) \\
\hline$N_{0}$ & Total number concentration & $4.461 \times 10^{9} \mathrm{~m}^{-3}$ & ClearfLo (Winter) ${ }^{*}$ \\
\hline$m_{0}$ & Standard mass mixing ratio & $1.8958 \times 10^{-5} \mathrm{~kg} \mathrm{~kg}^{-1}$ & Met Office NWP setting \\
\hline$p$ & Scaling power & $1 / 6$ & Clark et al. (2008) \\
\hline
\end{tabular}

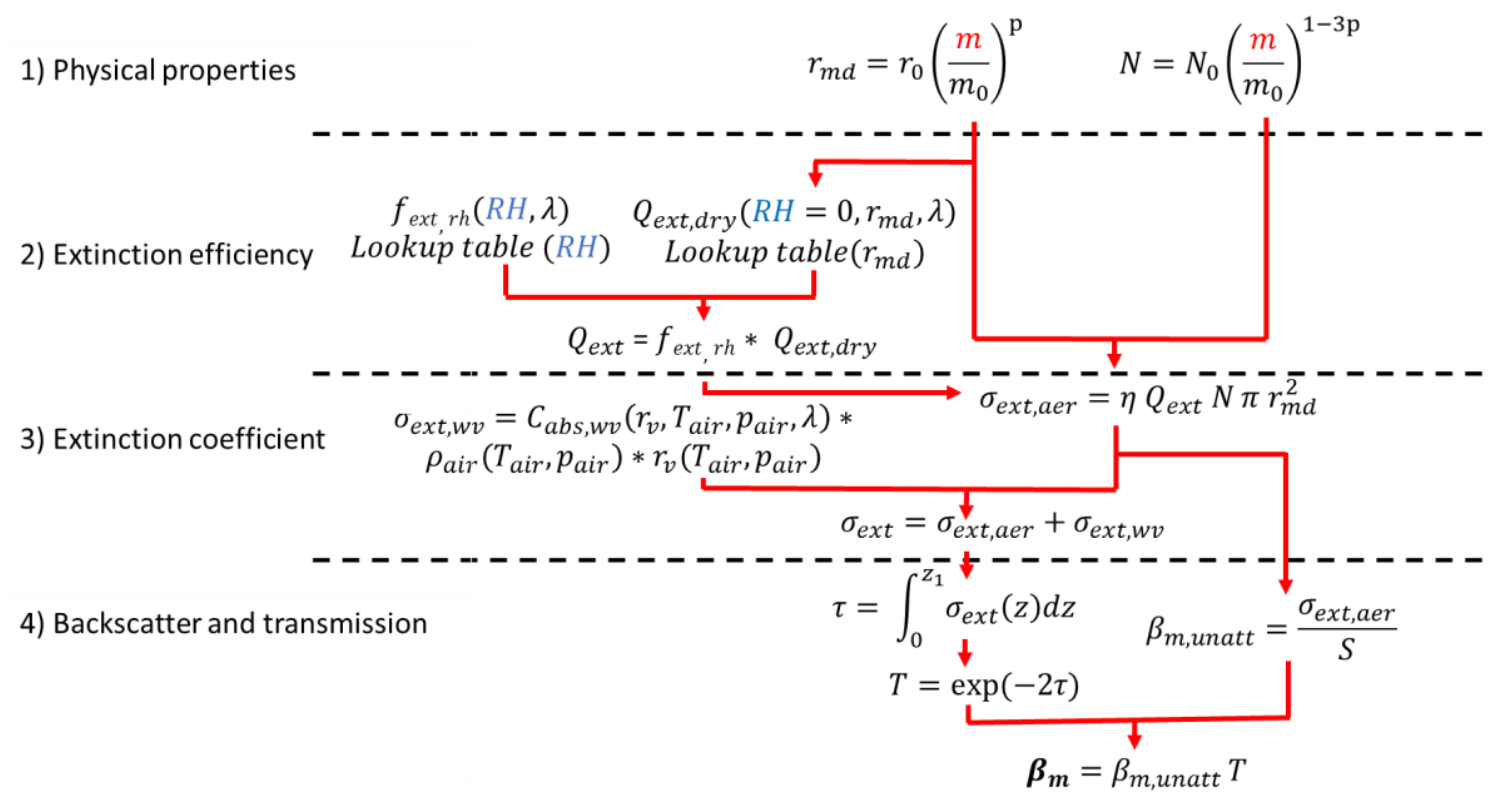

Figure 1: The aerosol forward operator (aerFO) to estimate attenuated backscatter from the NWP inputs of aerosol mass mixing ratio $(m)$ and relative humidity $(R H)$. See text for details and symbol definitions. 
As ALC observed scattering is a function of particle size, laser wavelength and atmospheric composition, these effects are incorporated in aerFO through $Q_{\text {ext }}$. $Q_{\text {ext }}$ is a function of laser wavelength, aerosol radius and complex index of refraction (Jacobson, 2005). In humid air, hydrophilic aerosols typically swell through hygroscopic growth, which increases particle size and can change the complex index of refraction. Both effects typically increase $Q_{e x t}$ for individual particles, and, consequently, for the bulk particle mixture. Hence, in the aerFO, a dry extinction efficiency $\left(Q_{\text {ext }, d r y}\right)$ is calculated and then multiplied by an extinction enhancement factor $f_{e x t, r h}$ (Figure 1, often called $f(R H)$ in the literature). $f_{e x t, r h}$ is a function of $R H$ and is calculated for each aerosol species separately. The assumed proportions of each aerosol are used to create a weighted $f_{\text {ext,rh }}$ for the bulk aerosol.

The actual aerosol composition (i.e. constituents and their proportions) is important (Seinfeld and Pandis, 2016) to both $Q_{e x t, d r y}$ and $f_{\text {ext,rh. }} Q_{e x t, d r y}$ is a function of the complex index of refraction, which differs between aerosol types. In sufficiently moist conditions $f_{e x t, \text { rh }}$ depends on both the particular aerosol's hygroscopicity and the critical $R H$ required for that aerosol constituent to change phase into a saturated solution, at which point the aerosol's optical characteristics change (Fitzgerald, 1975).

To incorporate a mixed aerosol composition in the calculation of $Q_{e x t, d r y}$, aerFO allows the user to specify the aerosol types and proportions, including the complex index of refraction for each aerosol species. The relative mass of each species is used to calculate a bulk complex index of refraction ( $n$ ) for the bulk aerosol mixture using the volume mixing method (Liu and Daum, 2008):

$$
n=\sum_{i} v_{i} n_{i}
$$

where $n_{i}$ is the partial refractive index and $v_{i}$ the volume fractional contribution of the $i$ th constituent. Here each aerosol constituent's complex index of refraction by wavelength (Table 2) is obtained from the MO NWP radiation suite SOCRATES (Manners et al., 2015). The aerosol species and their proportions implemented in the current MURK scheme are derived from airborne observations (Haywood et al., 2008, their Table 1). $Q_{\text {ext,dry }}$ is calculated from $n$ based on Mie theory at discrete wavelengths (0.2 nm resolution) assuming spherical aerosols (Jacobson, 2005). This assumption is often not met in reality (Aptowicz et al., 2006), so it introduces additional uncertainty to the aerFO estimates of $\beta_{m}$. However, this uncertainty decreases at higher $R H$ values when aerosols become swollen and hence more spherical. Comparison of the Mie code used to calculate $Q_{\text {ext,dry }}$ to Figure 13 of Haywood et al., (2008) found qualitatively minimal difference. Look up tables (LUT) of $Q_{e x t, d r y}$ are produced for dry radii ranging between $5 \times 10^{-10} \mathrm{~m}$ and $2 \times 10^{-6}$ $\mathrm{m}$, with a resolution of $5 \times 10^{-10} \mathrm{~m}$.

The MO SOCRATES radiation code is also used to create $f_{\text {ext, } r \text {. }}$. Based on the Edwards and Slingo, (1996) code, Mie theory calculations can be carried out with SOCRATES to derive mass scattering and absorption coefficients for different aerosol types. The effect of hygroscopic swelling is parameterised for $\mathrm{NH}_{4} \mathrm{NO}_{3}$ and $\left(\mathrm{NH}_{4}\right)_{2} \mathrm{SO}_{4}$ following Fitzgerald (1975), and organic carbon following Varutbangkul et al. (2006). Then subsequent changes in refractive index and density are used to calculate the optical properties using volume weighting. The SOCRATES suite is routinely updated and hence produces accurate $f_{\text {ext }, r h}$ curves based upon current knowledge. To create $f_{e x t, r}$, the complex indices of refraction by wavelength, geometric mass mean radius $\left(r_{g}\right)$, geometric standard deviation $\left(d_{g}\right)$ and a mean number concentration of the aerosol are required for each of the contributing species (Table 2). Sensitivity tests showed no difference in $f_{e x t, r h}$ using different number concentrations, therefore an arbitrary value of $8000 \mathrm{~cm}^{-3}$ is used. For all the aerosols, $r_{g}$ is set to $0.11 \mu \mathrm{m}$ (Haywood et al., 2008), i.e. the same value as $r_{0}$ (Table 1), and $d_{g}$ to 1.6. The latter is estimated from the first mode of the observed mass distribution in Regent's Park, London (Harrison et al., 2012). As with the aerosol type and proportions, $r_{g}$ and $d_{g}$ values can be set by the user.

Table 2: Sources of complex index of refraction from the SOCRATES code by aerosol species used for different ceilometer central wavelengths († CL31: 895-915 nm; Lufft CHM15K: $1064 \mathrm{~nm}$ ). *Absorption set to $\sim 1 / 3$ of the value for aged biomass burning organic matter based on MO scientific judgement. As volatile organic compounds were unavailable in SOCRATES, aged fossil fuel organic carbon is used instead (MO internal discussion, 04/2017). In this study, the bulk aerosol is assumed to contain ammonium sulphate, ammonium nitrate and organic compounds based on airborne observations from Haywood et al. (2008) (section 3.3).

\begin{tabular}{|l|l|l|l|l|}
\hline Aerosol Type & $\begin{array}{l}\text { Chemical } \\
\text { Symbol }\end{array}$ & Refractive Indices $\dagger$ & Part: Source \\
\cline { 3 - 4 } & & $895-915 \mathrm{~nm}$ & $1064 \mathrm{~nm}$ & \\
\hline Ammonium Nitrate & $\mathrm{NH}_{4} \mathrm{NO}_{3}$ & $1.61,1.70 \times 10^{-6} \mathrm{i}$ & $1.61,4.59 \times 10^{-6} \mathrm{i}$ & $\begin{array}{l}\text { Real: Weasted (1977); } \\
\text { Imaginary: Gosse et al. (1997) }\end{array}$ \\
\hline Ammonium Sulphate & $\left(\mathrm{NH}_{4}\right)_{2} \mathrm{SO}_{4}$ & $1.53,2.31 \times 10^{-7} \mathrm{i}$ & $1.51,2.22 \times 10^{-6} \mathrm{i}$ & $\begin{array}{l}\text { Real and Imaginary: Toon et al. } \\
\text { (1976) }\end{array}$ \\
\hline $\begin{array}{l}\text { Aged Fossil Fuel Organic } \\
\text { Carbon }\end{array}$ & N/A & $1.54,6.0 \times 10^{-3} \mathrm{i}$ & $1.54,6.0 \times 10^{-3} \mathrm{i}$ & $\begin{array}{l}\text { Real and Imaginary: Haywood et al. } \\
(2003)^{*}\end{array}$ \\
\hline
\end{tabular}


SOCRATES produces particle mass-specific scattering $C_{\text {scat,aer }}(R H)$ and absorption $C_{a b s, a e r}(R H)$ coefficients for $R H$ between 0 and 100 $\%$. These are used to calculate specific extinction coefficients $C_{\text {ext,aer }}(R H)$ :

$$
C_{\text {ext,aer }}(R H)=C_{\text {scat }, a e r}(R H)+C_{a b s, a e r}(R H)
$$

The extinction enhancement factor $f_{e x t, r h}$ is the ratio of $C_{e x t, a e r}$ at a given $R H$ level, to $C_{\text {ext,aer }}$ in the complete absence of humidity:

$$
f_{\text {ext }, r h}=\frac{C_{\text {ext }, a e r}(R H)}{C_{\text {ext,aer }}(R H=0)}
$$

$f_{\text {ext, } r h}$ is stored in a LUT for use in the aerFO.

As the amount of water vapour attenuation can be significant for some ALC wavelengths (e.g. Vaisala CL31, Wiegner and Gasteiger, 2015), the water vapour extinction $\left(\sigma_{e x t, w v}\right)$ needs to be incorporated into the aerFO:

$$
\sigma_{\text {ext }, w v}=C_{a b s, w v}\left(r_{v}, T_{a i r}, p_{\text {air }}\right) * \rho_{\text {air }}\left(T_{\text {air }}, p_{\text {air }}\right) * r_{v}\left(T_{\text {air }}, p_{\text {air }}\right)
$$

where $C_{a b s, w v}$ is the specific water vapour absorption coefficient, $r_{v}$ is the water vapour mixing ratio, $T_{a i r}$ the air temperature and $\rho_{a i r}$ the air density. As the scattering of light by water vapour is negligible at ALC wavelengths, $C_{a b s, w v}=C_{e x t, w v}$. $\rho_{a i r}$ and $r_{v}$ can be calculated using the NWP model outputs of $T_{a i r}, p_{a i r}$ and specific humidity $(q)$. $C_{a b s, w v}$ values were obtained using a line-by-line radiative transfer model LBLRTM 12.2 (Clough et al., 2005, 1992) were stored in a LUT after evaluation against atmospheric radiance spectra observed by an interferometer sounder.

Finally, the ALC wavelength range must be considered when estimating $Q_{e x t}$ and $\sigma_{e x t, w v}$ as the lasers do not operate strictly on one singular wavelength only. For example, the central wavelength of Vaisala CL31 ceilometers is reported to be $905 \pm 10 \mathrm{~nm}$ with a spectral width of $4 \mathrm{~nm}$ at full width half maximum (FWHM; section 3.1; Kotthaus et al., 2016). Therefore, to incorporate the effect of spectral width, Gaussian weighting with a FWHM of $4 \mathrm{~nm}$ is used when calculating $Q_{e x t, d r y}, f_{e x t, r h}$ and $\sigma_{\text {ext,wv }}$. The weight is applied to the LUT of $Q_{e x t, d r y}$, to $f_{e x t, r h}$ when calculating $C_{s c a t, a e r}(R H)$ and $C_{a b s, a e r}(R H)$ in SOCRATES and to the LUT of $C_{a b s, w v}$ before calculating $\sigma_{\text {ext }, w v}$.

\section{Methods}

\subsection{ALC data}

Vertical profiles of aerFO-derived $\beta_{m}$ (Section 2) are compared to $\beta_{o}$ from five London Urban Meteorological Observatory (LUMO) (Kotthaus and Grimmond, 2014; Table 3) Vaisala CL31 ALC, deployed at four sites in central London (Figure 2). Both hardware and firmware are critical for interpretation of the attenuated backscatter profiles observed, with older hardware (generation 311) generally having lower signal-to-noise ratios (SNR, Kotthaus et al., 2016). Also, ripple effects occur in some transmitters (generation CLT321) (section 3.1 in Kotthaus et al., 2016) that may deteriorate $\beta_{o}$ quality. Two generations of hardware are operated in LUMO during the study period analysed (Feb 2015 - Dec 2016; Table 3).

Attenuated backscatter profiles recorded at $15 \mathrm{~s}$ and $10 \mathrm{~m}$ resolution, are corrected for instrument-related background and near-range artefacts (Kotthaus et al., 2016). A centred moving average is applied with windows of $25 \mathrm{~min}$ (101 time steps) and $110 \mathrm{~m}$ (11 range gates) to increase the SNR (section 4.2 in Kotthaus et al., 2016). The vertical range is converted to height above ground level (agl). Comparison is undertaken for the lowest $2000 \mathrm{~m}$ agl as the atmospheric boundary layer did not exceed this limit during the case study days analysed (Kotthaus and Grimmond, 2018). The FWHM of the Vaisala CL31 laser wavelength is 4 nm, where FWHM is defined as the width across the function where the dependent variable is half of the peak value. The uncertainty in the Vaisala CL31 central wavelength is $< \pm 10 \mathrm{~nm}$ (Kotthaus et al., 2016), so here the average central wavelength of $905 \mathrm{~nm}$ is taken, as specified by the manufacturer. This is used as the centre in the Gaussian weighting function, along with the FWHM of $4 \mathrm{~nm}$, to calculate $Q_{e x t, d r y}, f_{e x t, r h}$ and $\sigma_{e x t, w v}$. For the comparison, the nearest $\beta_{o}$ vertical profile in time was used for each $\beta_{m}$ profile. In section 5.2, the near-surface model values are compared to the second ceilometer range gate ( $20 \mathrm{~m}$ above sensor) as the first gate is prone to augmented noise (Kotthaus et al., 2016). The CL31 reaches complete optical overlap at $70 \mathrm{~m}$ and observations below this height are corrected. Further, near-range artefacts (Kotthaus et al., 2016) are accounted for so that the profile data can be used basically from the first range gate. For the comparison of vertical profiles (section 5.3) the value of $\beta_{o}$ at the nearest vertical height to the $\beta_{m}$ level is selected.

The smoothed ALC signal profiles of attenuated backscatter are calibrated using a daily calibration coefficient. The calibration coefficients are calculated using the 'cloud method'(O'Connor et al., 2004). An apparent lidar ratio in stratocumulus cloud is estimates from the attenuated backscatter and then scaled to the lidar ratio of stratocumulus cloud (18.8 sr). The calibration coefficients are calculated based on the attenuated backscatter profiles corrected for instrument-related background (Kotthaus et al., 2016) using the automatic procedure of Hopkin et al. (2017, n.d.). This requires stratocumulus clouds to be present and some knowledge of vertical 
Warren E, C Charlton-Perez, S Kotthaus, H Lean, S Ballard, E Hopkin, S Grimmond 2018 Evaluation of forward-modelled attenuated backscatter using an urban ceilometer network in London under clear-sky conditions Atmospheric Environment https://doi.org/10.1016/j.atmosenv.2018.04.045

profiles of water vapour. UKV water vapour vertical profiles, for the nearest grid-point to KSSW (Figure 2) were used to account for water vapour absorption. As we focus on clear and stratocumulus free days, the time series of calibration coefficients for days with stratocumulus cloud were interpolated for each instrument, with key hardware changes and window transmission (i.e. cleanliness [\%]) accounted for. The daily calibration coefficients LUT is based on time period averages or linear regression relations with reported window transmission for each instrument.

Table 3: Ceilometers at each site (Figure 2) from LUMO network (Kotthaus and Grimmond, 2014). ALC data analysed for the spring comparison (*) and 12 cloud-free days between 5/2/2015 - 31/12/2016 [2015: 14/4, 15/4, 21/4, 11/6, 2016: 19/1; 4/5; 23/8, 11/9, 25/11, 29/11, 30/11, 4/12]. All heights are metres above ground level $(\mathrm{m}$ agl $) . \dagger$ Older (311) and newer (321) generation.

\begin{tabular}{|c|c|c|c|c|c|}
\hline Site & Ceilometer ID & hardware generation $^{\dagger}$ & firmware versions & Height [m agl] & Analysis \\
\hline KSS45W & CL31-A & 311 & $1.71,1.72$ & 32.9 & 4 days \\
\hline IMU & CL31-A & 311 & $1.72,1.74$ & 91.0 & 7 days \\
\hline RGS & CL31-B & 311 & $1.71,1.72,1.74$ & 8.7 & 8 days \\
\hline MR & CL31-C & 321 & $2.02,2.03,2.04$ & 4.5 & 12 days * \\
\hline NK & CL31-D & 321 & $2.02,2.03,2.04$ & 3.8 & 5 days \\
\hline NK & CL31-E & 321 & $2.03,2.04$ & 3.8 & 7 days \\
\hline
\end{tabular}

\subsection{Ancillary data}

To aid interpretation of $\beta_{m}$ and $\beta_{o}$ differences, in-situ surface observations (4, Figure 2) are used, including hourly $P M_{10}$ from three London Air Quality Network sites (LAQN, King's College London, 2016) near LUMO ceilometer sites (Figure 2). Because the MURK bulk aerosol is the total mass of aerosol of all sizes and $P M_{10}$ is the total mass of aerosol with diameters below $10 \mu \mathrm{m}$, the two are not directly comparable. $R H$ sampled using the Vaisala WXT520 sensors at $5 \mathrm{~s}$ and averaged to $60 \mathrm{~s}$ (Kotthaus and Grimmond, 2014) is used to assess modelled near-surface $R H$. Turbulent sensible heat fluxes derived from CSAT3 3D sonic anemometer observations (flux processing details in Kotthaus and Grimmond, 2014) are compared with turbulent surface fluxes from the model.

Table 4: Ancillary instrumentation at each site from LUMO (Kotthaus and Grimmond, 2014) and LAQN (Mittal et al., 2016) networks. WS: weather station model. All heights are meters above ground level ( $m$ agl)

\begin{tabular}{|c|c|c|c|c|c|c|}
\hline Site & Height [m agl] & Site & Height [m agl] & LAQN site & Closest LUMO site & Height [m agl] \\
\hline \multicolumn{2}{|c|}{ WS: Davis Vintage Pro } & \multicolumn{2}{|c|}{ WS: Vaisala WXT520 } & \multicolumn{3}{|c|}{ Filter Dynamics Measurement Systems } \\
\hline BCT & 145.0 & KSK & 38.8 & MY1 & MR & 4.5 \\
\hline $\mathrm{BFCL}$ & 21.0 & KSNW & 47.1 & KC1 & NK & 2.8 \\
\hline BGH & 49.0 & KSSW & 41.3 & KC2 & RGS & 3.6 \\
\hline IML & 25.5 & \multicolumn{2}{|c|}{ Sonic anemometer: Campbell Sci. CSAT3 } & & & \\
\hline IMU & 91.0 & KSSW & 46.2 & & & \\
\hline
\end{tabular}

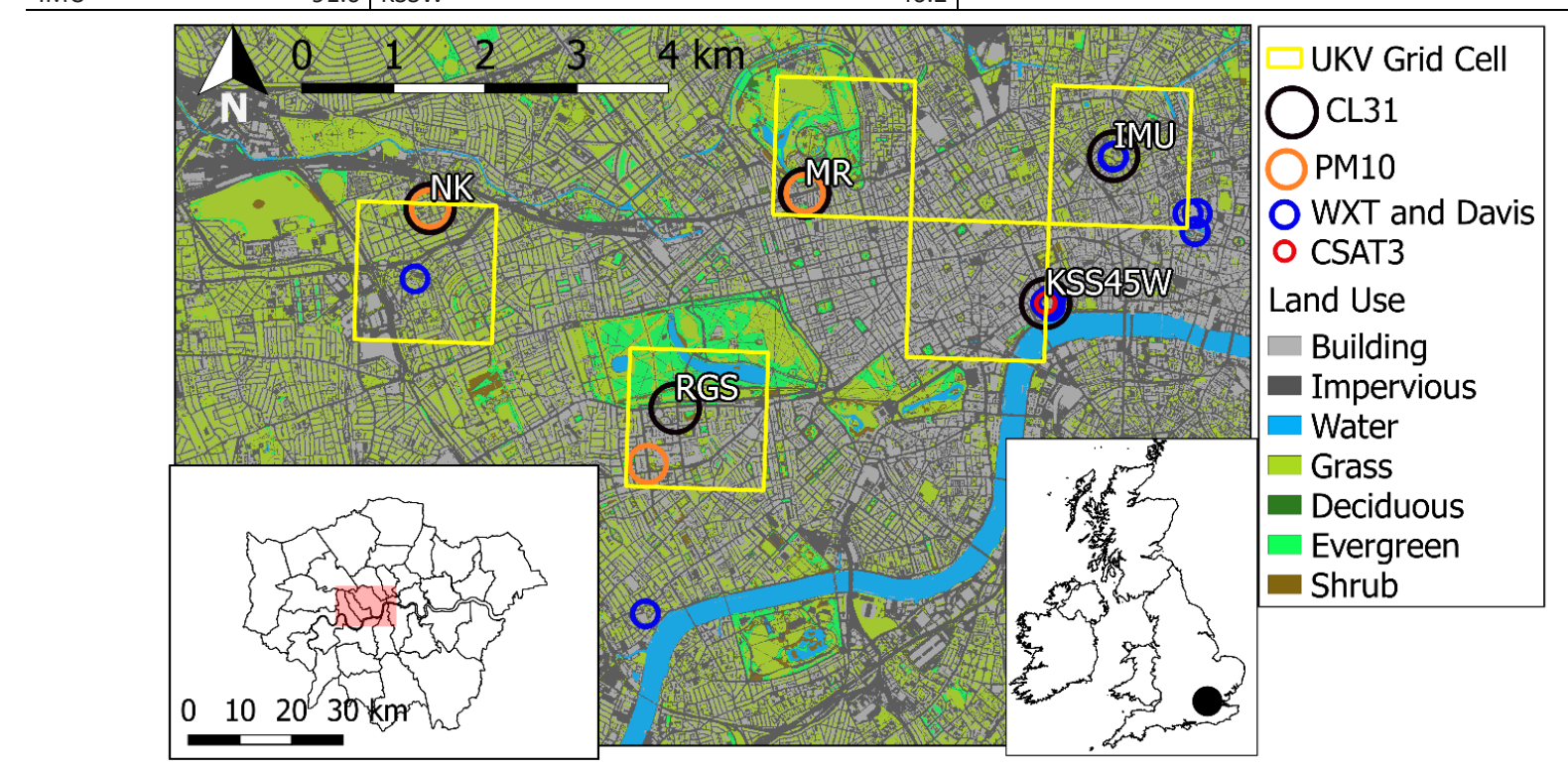

Figure 2: LUMO and LAQN measurement sites (ceilometer instruments: Table 3; ancillary instruments: 4) in central London with relevant UKV $1.5 \times 1.5 \mathrm{~km}$ grid cells (yellow), and surface cover type (data source described in Lindberg and Grimmond, 2011); within Greater London and the British Isles (insets). 


\subsection{Data from the NWP model}

The NWP inputs $\left(R H, m_{M U R K}\right)$ used to drive the aerFO are from the 3 hourly, $36 \mathrm{~h} \mathrm{MO}$ operational UKV forecast (1.5 $\left.\mathrm{km}\right)$. The aerFO calculations of $\beta_{m}$ are performed hourly, from $3 \mathrm{~h}$ after the forecast begins, using archived UKV data for 5 grid cells (Figure 2).

The MO UKV MURK aerosol is a single mass mixing ratio $\left(m_{M U R K}, \mathrm{~kg} \mathrm{~kg}^{-1}\right)$ and a passive tracer. It represents a bulk aerosol composed of ammonium sulphate, ammonium nitrate and organic carbon (Table 2) based on the aerosol species measured by Haywood et al. (2008) during four flights around the UK's coast.

The data analysis is undertaken after the aerosol model changed (5 February 2015) and the MURK ancillaries were updated to improve the visibility forecast (Appendix 1). For comparison against $\mathrm{PM}_{10}$ concentrations (section 5.2), $m_{M U R K}$ units are converted to $\mathrm{kg} \mathrm{m}^{-3}$ by multiplying it with the UVK air density, derived from UKV air temperature and pressure fields.

In the UKV, JULES (Best et al., 2011) accounts for the land surface effects. On 16 March 2016 the urban land surface option was upgraded from the 1-tile scheme (Best, 1998) (hereafter the Best scheme) to MORUSES (Bohnenstengel et al., 2011; Porson et al., 2010). The latter aims to improve the parameterisation of surface-atmosphere interactions in cities through a better representation of the heat and moisture fluxes from urban surfaces. This is done using two urban tiles which account for the street canyon (walls, road) and the roof, respectively.

\subsection{Study periods}

To evaluate the NWP output of $m_{M U R K}$ and $R H$, and explore the possible implications of changing the urban surface scheme, analysis is undertaken for two spring cases (14 April 2015 and 04 May 2016) from before and after the change to MORUSES respectively (section 5.1). A more general evaluation of $\beta_{m}$ is performed based on 11 cloud-free days between 5 February 2015 and 31 December 2016 (Table 3). These cases have data for at least 2 ALC but without clouds at any height for $>99 \%$ of the day (section 5).

\section{Sensitivity Analyses}

Several simplifying assumptions are made within the aerFO and about its inputs (Section 2). To understand the implications and uncertainties associated with these, sensitivity analyses are conducted, addressing potential issues with the aerosol species (section 4.2), laser wavelength (section 4.3) and NWP model variables required as input by the aerFO (section 4.4 and 4.5).

\subsection{Sensitivity of total number concentration ( $\left.N_{0}\right)$ to defined accumulation radii range}

To calculate $N_{0}$, the accumulation range of the aerosol distribution needs to be defined, so that $N_{0}$ is representative of the same mode as ro. However, aerosol distributions change in time and space (Rodriguez et al., 2007), such that the range of radii for the accumulation mode varies. Therefore, it is important to test the implications of this assumption in calculating $N_{0}$.

A comparison of different radii ranges reveals that $N_{0}$ is highly sensitive to the range of radius used to define the accumulation range, and specifically the lowest limit used (Table 5). Reducing the lower limit of the range can extend into the finer mode of the aerosol distribution, which dominates the number distribution of total aerosol (e.g. Figure 13 in Harrison et al., 2012). Increasing the upper limit has a smaller effect due to the fewer number of aerosols at larger sizes. The choice of radii range could consequently have a large impact on $\beta_{m}$ as $N_{0} \propto N \propto \sigma_{\text {ext }}$. For example, $\beta_{m \text {, unat }}$ is $15.3 \%$ smaller if the radii range is $0.05-0.7$ instead of $0.04-0.7 \mu \mathrm{m}$, and 53.4 $\%$ larger if a radii range of $0.02-0.7 \mu \mathrm{m}$ is used, simply due to the variation in estimated $N_{0}$ (Table 5). Given the high sensitivity of $N_{0}$ to radii range, future analysis of additional aerosol distribution observations could inform the definition of a more suitable radius range and reduce the uncertainty in estimating $\beta_{m}$.

Table 5: Total number concentration $\left(N_{0}\right)$ calculated using different ranges of radius to define the accumulation range of the total aerosol distribution. Example extinction $\left(\sigma_{\mathrm{ext}}\right)$ and unattenuated backscatter $\left(\beta_{m}\right.$, unatt $)$ coefficients calculated for $m=18.0 \mu \mathrm{g} \mathrm{kg-1}$ and $\mathrm{RH}=60 \% .+$ Currently used in aerFO.

\begin{tabular}{|r|l|r|r|}
\hline $\begin{array}{l}\text { Total number concentration } \\
\left(N_{0}, \mathrm{~cm}^{-3}\right)\end{array}$ & $\begin{array}{l}\text { Radii range } \\
(\mu \mathrm{m})\end{array}$ & $\begin{array}{l}\text { Extinction coefficient }\left(\sigma_{e x t},\right. \\
\left.m^{-1}\right)\end{array}$ & $\left.\begin{array}{l}\text { Unattenuated backscatter } \\
\text { coefficient }\left(\beta_{m}, \text { unat }\right.\end{array} \mathrm{m}^{-1} s r^{-1}\right)$ \\
\hline 3769 & $0.05-0.7$ & $1.49 \times 10^{-5}$ & $2.48 \times 10^{-7}$ \\
\hline 4461 & $0.04-0.7$ & $1.76 \times 10^{-5}$ & $2.94 \times 10^{-7}$ \\
\hline 5426 & $0.03-0.7$ & $2.15 \times 10^{-5}$ & $3.58 \times 10^{-7}$ \\
\hline 6824 & $0.02-0.7$ & $2.70 \times 10^{-5}$ & $4.50 \times 10^{-7}$ \\
\hline 4471 & $0.04-1.0$ & $1.77 \times 10^{-5}$ & $2.95 \times 10^{-7}$ \\
\hline
\end{tabular}




\subsection{Sensitivity of extinction efficiency to aerosol species}

To calculate $Q_{e x t}$, aerosol types and their relative volumes are required from the NWP model (section 2). Currently, for consistency with $m_{M U R K}$ assumptions (Appendix 1), aerFO assumes that the bulk aerosol is externally mixed and consists of ammonium sulphate $\left(\left(\mathrm{NH}_{4}\right)_{2} \mathrm{SO}_{4}\right)$, ammonium nitrate $\left(\mathrm{NH}_{4} \mathrm{NO}_{3}\right)$ and organic carbon $(\mathrm{OC})$, with fixed relative volumes in space and time. However, as other aerosol types may be present in addition (e.g. salt and black carbon, Seinfeld and Pandis, 2016) and the relative fractions are likely to vary (e.g. at monthly, daily and hourly time scales; Harrison et al., 2012; Young et al., 2015), implications of these assumptions are assessed.

For this sensitivity study, $f_{e x t, r h}$ and $Q_{e x t, d r y}$ are varied separately for seven commonly observed aerosol types (Seinfeld and Pandis, 2016). SOCRATES is used to calculate $f_{e x t, r h}$ (section 2). Each aerosol is assumed to have an idealised distribution with a fixed geometric mean radius $\left(r_{g}\right)$ of $0.11 \mu \mathrm{m}$ (Haywood et al., 2008) and fixed geometric standard deviation $\left(d_{g}\right)$ of 1.6 except for salt. Salt (generic $\mathrm{NaCl}$ ), can be relatively coarse compared to $\left(\mathrm{NH}_{4}\right)_{2} \mathrm{SO}_{4},\left(\mathrm{NH}_{4} \mathrm{NO}_{3}\right)$ and $\mathrm{OC}$, so here $r_{g}$ is set to $8.0 \mu \mathrm{m}$. Given black carbon's highly hygrophobic nature, $f_{\text {ext, } r h}$ is set to 1 (Forster et al., 2007) for this species. Calculations are undertaken for the Vaisala CL31 ceilometer laser wavelengths ( $\lambda=905 \mathrm{~nm}$ with FWHM of $4 \mathrm{~nm}$, section 3.1).

Large differences in $f_{\text {ext, } r h}$ occur between the different aerosol species, with the highest discrepancies between salt and black carbon (Figure 3). The variation in $f_{e x t, r h}$ reflects differences in the hygroscopic nature of the aerosol types and hygroscopic growth with water condensation (Haeffelin et al., 2016). These large differences in $f_{\text {ext }, r h}$ between commonly observed aerosol types suggest that using only $\left(\mathrm{NH}_{4}\right)_{2} \mathrm{SO}_{4}, \mathrm{NH}_{4} \mathrm{NO}_{3}$ and aged fossil-fuel (for OC) could lead to a poor estimation of the "true" $f_{e x t, r h \text {. }}$

The uncertainty in $f_{\text {ext, } r h}$ will increase as the unaccounted aerosol proportion increases, especially if its $f_{e x t, r h}$ is significantly different from the applied proxies. For instance, the mean mass fraction of black carbon can be large in some cities (up to 17\% during winter in London, Liu et al., 2014), and therefore omitting it (as e.g. in the MURK-mixture; Appendix 1) could lead to an overestimation of hygroscopic growth . Similarly, the sea salt fraction can increase from episodic events (e.g. sea breezes and gales), or be naturally high in cities exposed to maritime flows such as Glasgow (AQEG, 2005). However, some combinations of aerosols may have compensatory effects on $f_{e x t, r h}$; for example, salt (high $\left.f_{e x t, r h}\right)$ and black carbon (low $\left.f_{e x t, r h}\right)$ in approximately equal amounts.

The uncertainty in $f_{\text {ext, } r h}$ increases with increasing $R H$ (Figure 3) as growth rates differ by aerosol type above the critical RH value of approximately $40 \%$. Black carbon is notably different to all other species tested as it is insensitive to changes in RH. The uncertainty is highest near saturated conditions, where the particles would continue to grow into cloud and rain droplets. This indicates $\beta_{m}$ needs to be interpreted carefully in high humidity conditions, however, the large uncertainty at high $R H$ is not considered critical here as the aerFO focuses on cloud-free conditions only.

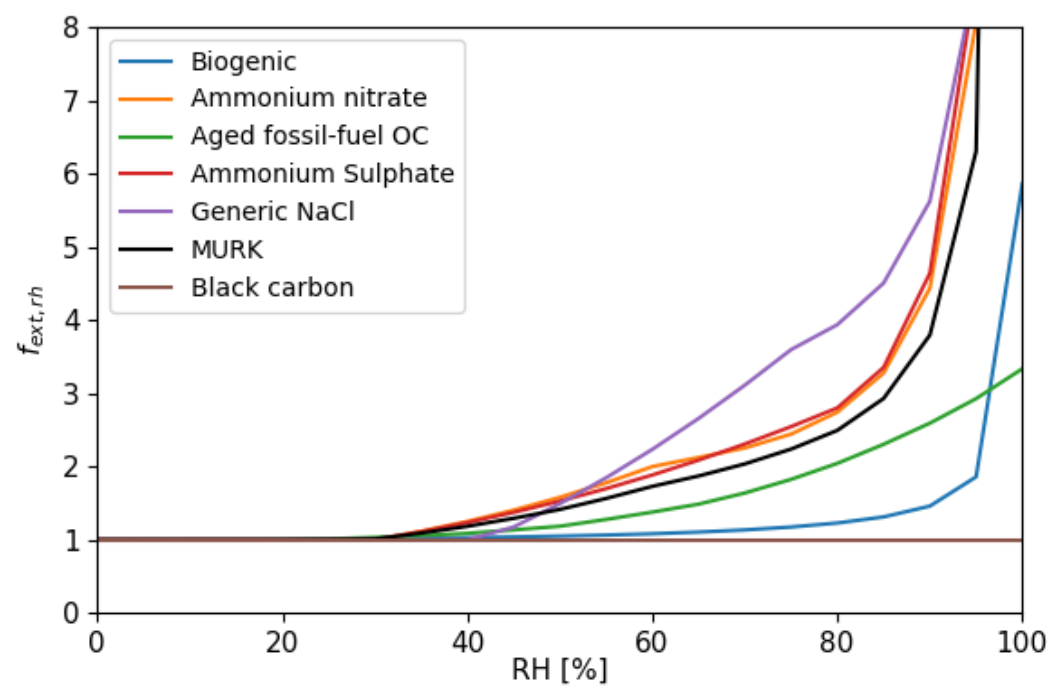

Figure 3: Extinction enhancement factors $\left(f_{\text {ext,rh }}\right)$ as a function of relative humidity $(R H)$ for several aerosol types commonly observed in urban areas for a mean wavelength of $905 \mathrm{~nm}$, with a full width half maximum of $4 \mathrm{~nm}$. MURK (black) is a bulk aerosol type including ammonium sulphate $\left(\left(\mathrm{NH}_{4}\right)_{2} \mathrm{SO}_{4}\right)$, ammonium nitrate $\left(\mathrm{NH}_{4} \mathrm{NO}_{3}\right)$ and aged fossil-fuel organic compounds (to represent organic carbon (OC)) used to represent the aerosol field in the UKV. The dry mean geometric radius $\left(r_{g}\right)$ of all aerosol types is assumed to be $0.11 \mu \mathrm{m}$ except for generic $\mathrm{NaCl}\left(r_{g}=8.0 \mu \mathrm{m}\right)$. Geometric standard deviation $\left(d_{g}\right)$ is set to $1.6 \mu \mathrm{m}$ for all aerosols. 
The variation of urban aerosol types (Harrison et al., 2012; Seinfeld and Pandis, 2016; Young et al., 2015) also impacts the dry scattering and absorption properties of the bulk particle (defined by their complex index of refraction, Jacobson, 2005) and causes differences in extinction. A clear impact of particle type on $Q_{e x t, d r y}$ is evident (Figure 4). Notably, the extinction efficiency of black carbon shows a different pattern compared to the other species because of its relatively high absorptivity and low scattering properties. In cities where black carbon is a critical proportion of the mass, for example in London (Liu et al., 2014), Ostrava (Kucbel et al., 2017) or Beijing (Ji et al., 2017), bulk aerosol characteristics should account for black carbon with its distinct characteristics.

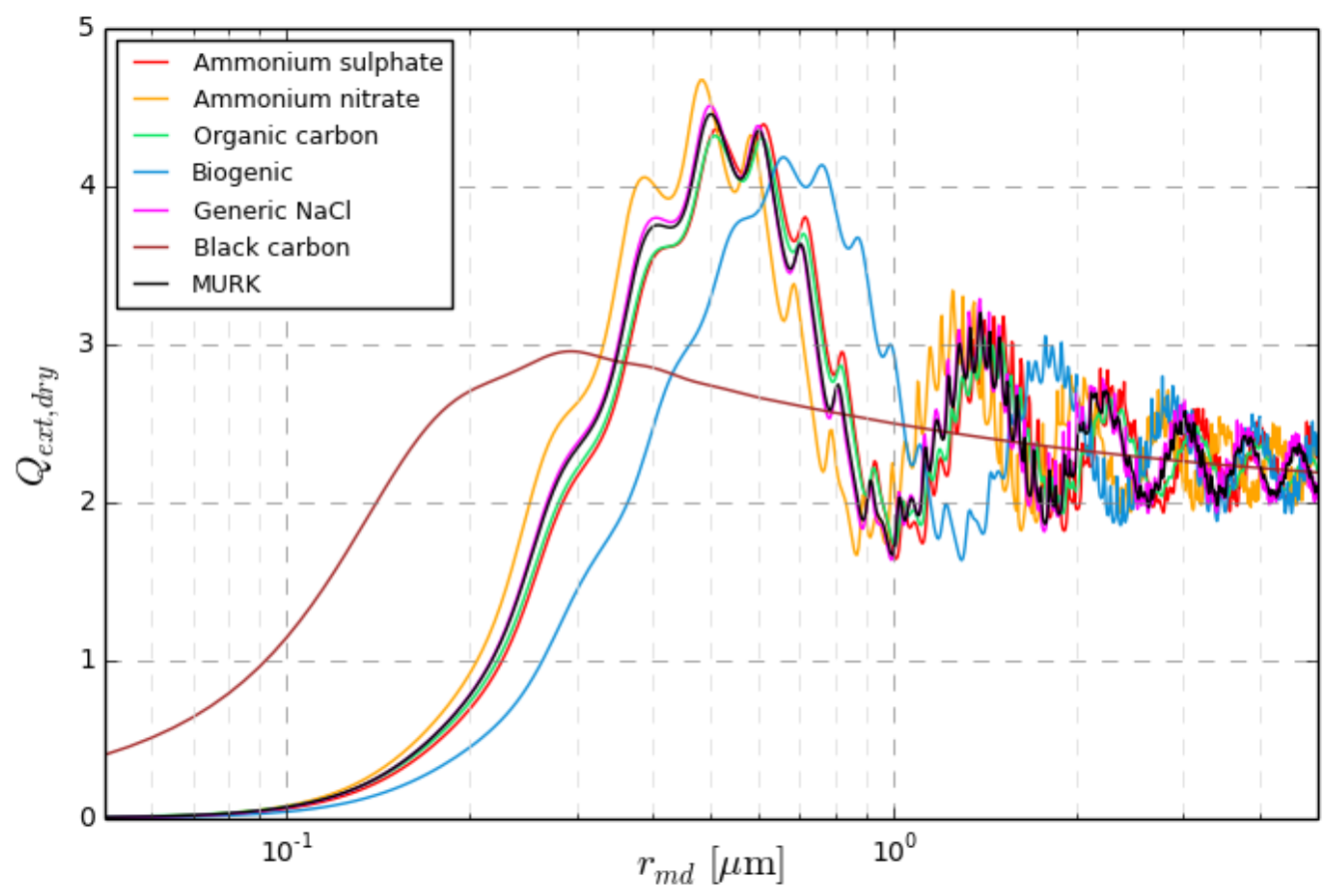

Figure 4: Dry extinction efficiency $\left(Q_{\text {ext,dry }}\right)$ calculated for several aerosol types (no particle swelling) observed in urban areas and the bulk aerosol composition of MURK (section 2), for a range of radius $r_{m d .}$ Calculations are based on Mie theory and a laser wavelength of $905 \mathrm{~nm}$.

\subsection{Sensitivity of extinction efficiency to lidar central wavelength}

The central wavelength of ALC lasers differs between models (e.g. Vaisala CT25K, CL31, CL51 at 905 nm; Lufft CHM15K at 1064 nm (Flynn, 2004; Lufft, 2016)). Furthermore, some uncertainty is associated with the nominal centre wavelength of individual sensors of the same model (Kotthaus et al., 2016). Therefore the implications of wavelength variation on $f_{\text {ext }, r h}$ and $Q_{\text {ext,dry }}$ uncertainty are explored.

The variation with respect to wavelength from the nominal $905 \mathrm{~nm}$ (e.g. Vaisala) was assessed across the range 895 to $915 \mathrm{~nm}(1 \mathrm{~nm}$ resolution) because the centre wavelength uncertainty may vary by $< \pm 10 \mathrm{~nm}$ (Kotthaus et al., 2016). $f_{\text {ext }, \text { rh }}$ across this wavelength range was found to differ from the factor at the nominal centre wavelength by maximal $2 \%$, so that this uncertainty can be neglected (see Figure S.1 in supplemental materials). However, the variation in $Q_{e x t, d r y}$ across the wavelength range was larger, and greatest at a mean radius of $\sim 0.8-2 \mu \mathrm{m}$ (Figure 5). A detected wavelike pattern with respect to radius can be explained by $Q_{e x t, d r y}$ becoming increasingly out of phase for each wavelength, with respect to values calculated at $905 \mathrm{~nm}$ For typical $r_{m d}$ estimates $(0.08-0.15 \mu \mathrm{m})$ and mass mixing ratios $\left(1 \mu \mathrm{g} \mathrm{kg}^{-1}<m_{M U R K}<100 \mu \mathrm{g} \mathrm{kg}^{-1}\right)$, the effect of varying wavelength on $Q_{e x t, d r y}$ reaches up to $6 \%$ for MURK and up to $8 \%$ for ammonium sulphate and ammonium nitrate. This relatively high sensitivity of $Q_{\text {ext,dry }}$ to small variations in $\lambda$ suggests results of the aerFO could be improved if the exact centre wavelength of the laser was known. However, where this information is not available from the manufacturer, this uncertainty remains. 


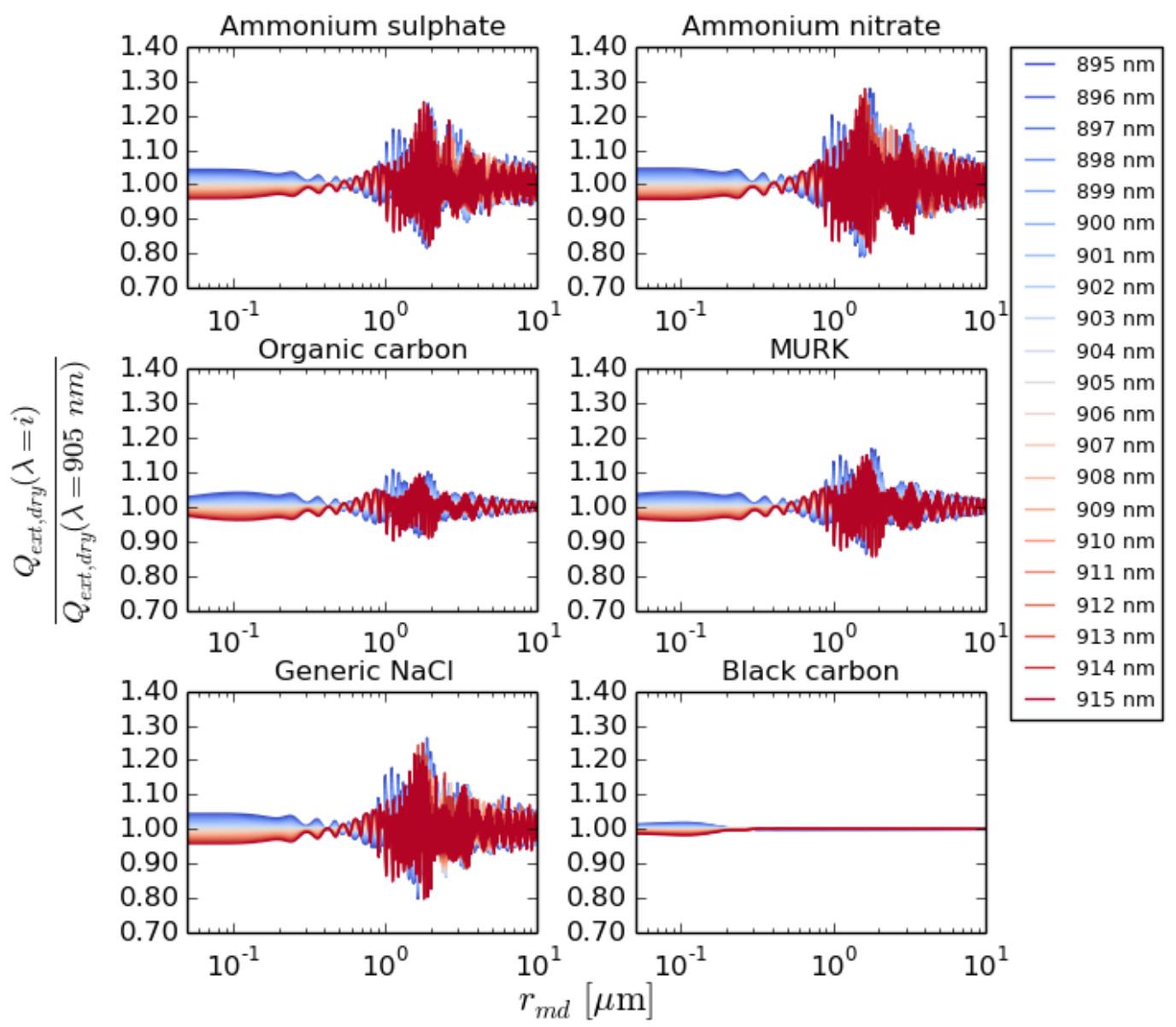

Figure 5: Dry extinction coefficient $\left(Q_{\text {ext,dry }}\right)$ variation with mean aerosol radius $r_{m d}[\mu m]$ for different monochromatic wavelengths (colour) normalized by results at $905 \mathrm{~nm}$ for MURK; MURK's three constituents: ammonium sulphate, ammonium nitrate and organic carbon; and two additional common aerosol species (generic sea salt and black carbon). Particle swelling is not accounted for in this test.

Given multiple ALC networks can contain different instruments, with largely different wavelengths, the importance of this interinstrument wavelength variation on estimating $\beta_{m}$ was briefly explored. To do this, the impact of laser wavelength on $f_{e x t, r h}$ and $Q_{e x t, d r y}$ for the two most common ALC wavelength (1064 nm, FWHM of $0.1 \mathrm{~nm}$ e.g. Lufft, and $905 \mathrm{~nm}$, FWHM of 4 nm, e.g. Vaisala) was compared. The ratio of the enhancement factor for the two wavelengths is calculated for MURK and the three MURK aerosols constituents (Figure 6). As $f_{\text {ext,rh }}$ differs by up to $\sim 30 \%$ between these wavelengths, the aerFO allows the user to specify the centre laser wavelength and FWHM to enable appropriate comparison of modelled and observed attenuated backscatter.

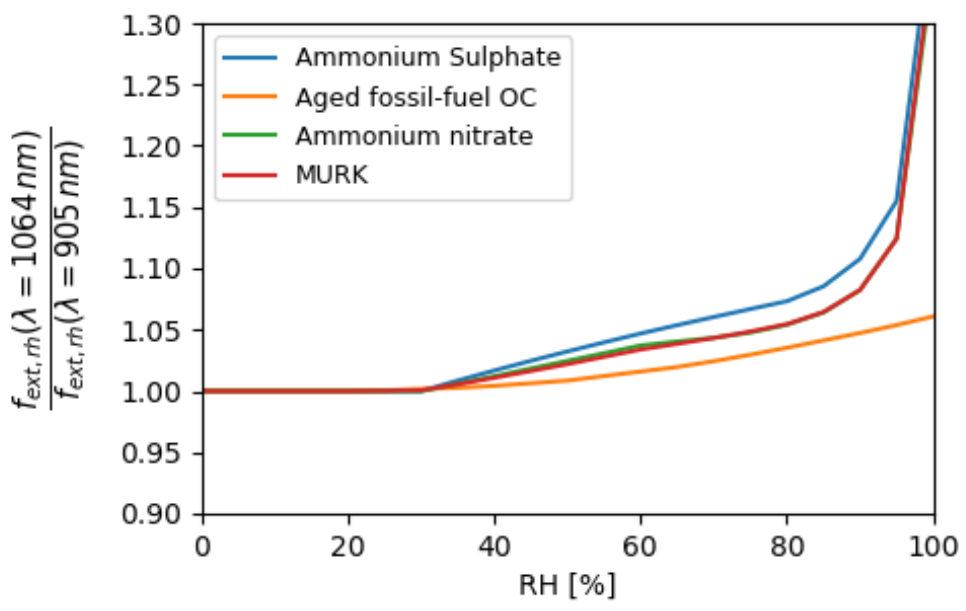

Figure 6: Extinction enhancement coefficient $\left(f_{\text {ext, } r \mathrm{r}}\right)$ ratio between $1064 \mathrm{~nm}$ with $\mathrm{FWHM}=0.1 \mathrm{~nm}$ and $905 \mathrm{~nm}$ with $\mathrm{FWHM}=4 \mathrm{~nm}$, against RH, for MURK and the different aerosol species within MURK. Note: results for ammonium nitrate (green) are almost identical to those for MURK (red). 
As for $f_{\text {ext, } r h}, Q_{\text {ext,dry }}$ results clearly differ when calculated for the two most common ALC centre wavelengths (i.e. 905 and $1064 \mathrm{~nm}$; Figure 7) for common aerosol radii tested in the aerFO $(0.08-0.15 \mu \mathrm{m})$. At $1064 \mathrm{~nm}, Q_{e x t, d r y}$ of MURK can be up to $50 \%$ lower compared to the results at $905 \mathrm{~nm}$ (Figure 7). This reaffirms the conclusion that the aerFO must account for ALC laser wavelength in order to accurately estimate $Q_{e x t, d r y}$. Hence, sensor networks with a mix of ALC types, must account for these differences by calculating $Q_{e x t, d r y}$ separately for the operated laser wavelengths.

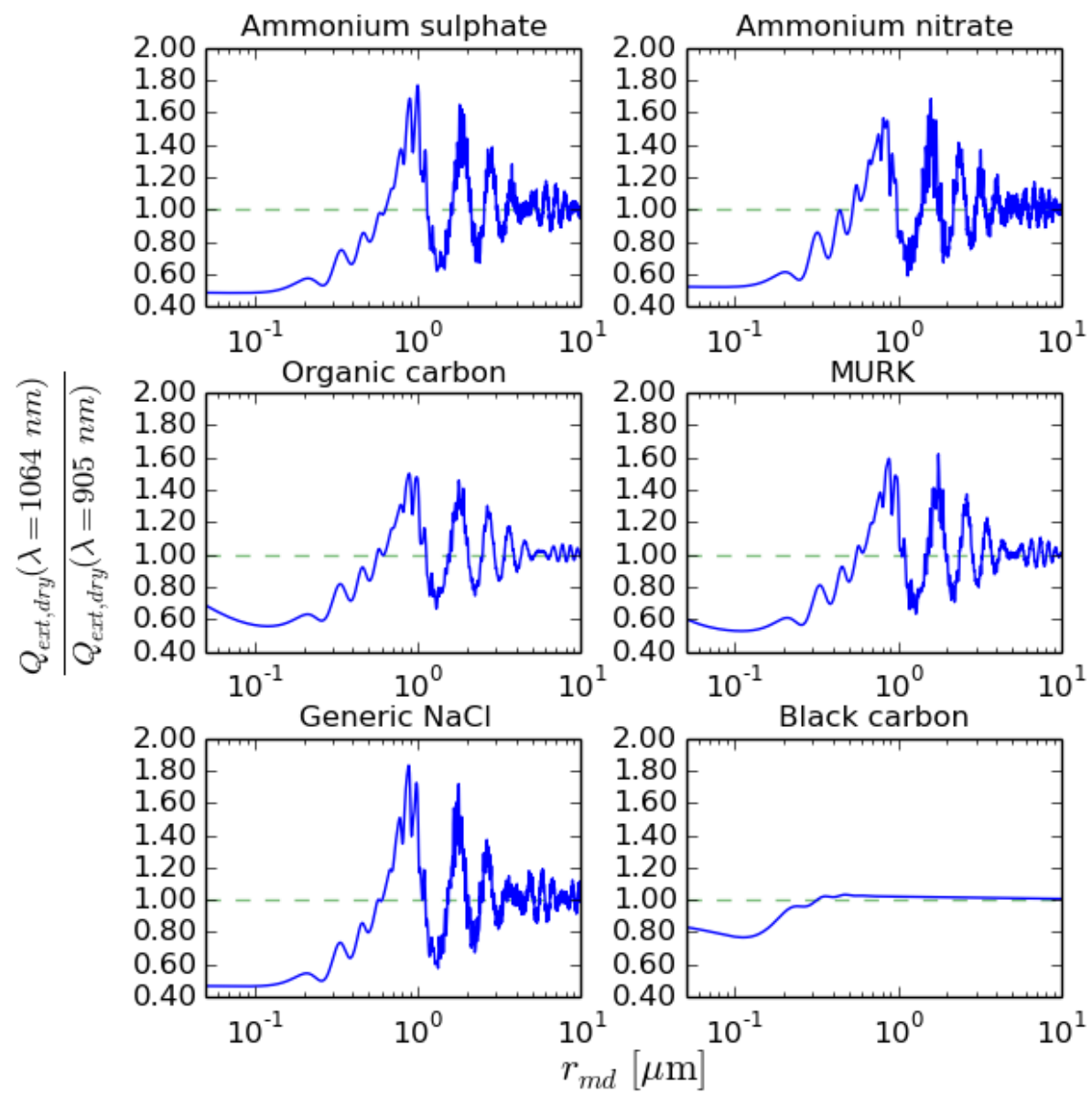

Figure 7: As Figure 5Error! Reference source not found., but for different central wavelengths commonly used by ALC, i.e. $905 \mathrm{~nm}$ (e.g. Vaisala) and 1064 nm (e.g. Lufft). Dashed line represents a constant ratio of 1 .

\subsection{Sensitivity of forward-modelled unattenuated backscatter to relative humidity and aerosol mass mixing ratio}

The sensitivity of aerFO calculated unattenuated backscatter $\left(\beta_{m}\right.$, unatt $)$ to aerosol mass mixing ratio $m$ and relative humidity $R H$ was tested to inform analysis of $\beta_{m}$ and to attribute inaccuracies correctly to either $m$ or $R H$. $\beta_{m}$, unatt increases with increasing $m$ and $R H$ (Figure 8). At higher $m$ values there is greater sensitivity, mainly because $\beta_{m \text {, unatt }}$ is $\propto \sigma_{e x t}$ and $\sigma_{e x t} \propto N$ and $\sigma_{e x t} \propto r_{m d^{2}}$ (Figure 1). Additionally, the relation of $\sigma_{e x t}$ to $Q_{e x t, d r y}$ also increases exponentially for common aerosol size regimes $\left(r_{m d} \cong 0.07-0.15 \mu \mathrm{m}\right.$, with 1 $\left.>m>100 \mu \mathrm{g} \mathrm{kg}^{-1}\right)$.

The increase in $\beta_{m \text {, unatt }}$ with $R H$ reveals a stronger exponential relation. The sensitivity of $\beta_{m \text {, unatt }}$ to $R H$ is low when $\mathrm{RH}<60 \%$, but greatly increases if $R H>60 \%$. This reflects both the physical growth of particle size and the change in the complex index of refraction caused by hygroscopic swelling, which is parameterised through $f_{\text {ext, rh }}$ (Figure 8 ). This relation suggests small inaccuracies in $R H$ at high $R H$ levels could have a large impact on $\beta_{m}$, unatt and therefore $\beta_{m}$. However, variations in $R H$ at drier conditions (< 60\%) have little effect on the $\beta_{m}$, unatt estimated. 


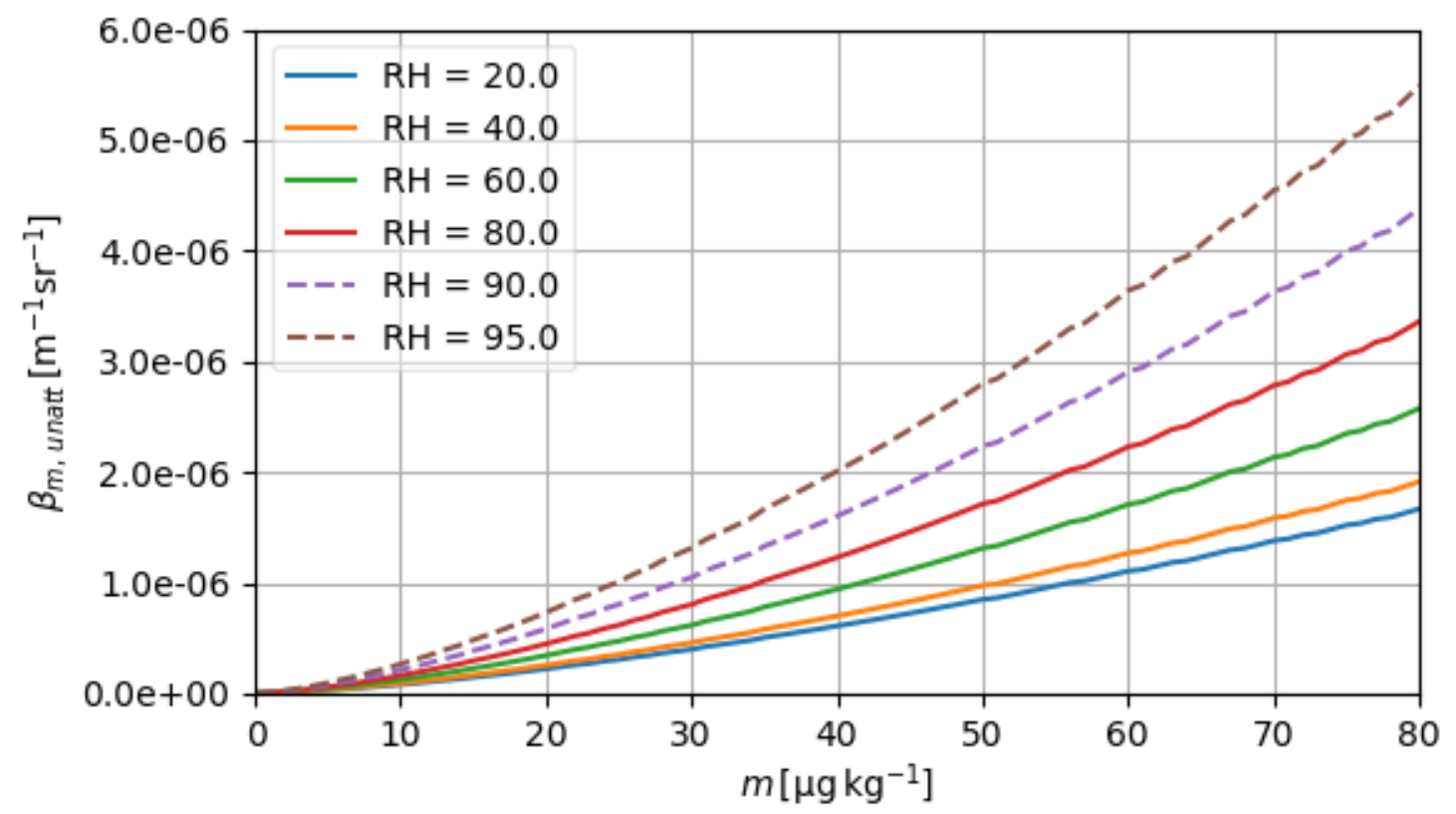

Figure 8: Sensitivity of aerFO estimated unattenuated backscatter ( $\beta_{m, \text { unatt }}$ [ $\left[\mathrm{m}^{-1} \mathrm{sr}^{-1}\right.$ ] to modelled aerosol mass $m\left[\mu \mathrm{g} \mathrm{kg}^{-1}\right]$ for different $\mathrm{RH}[\%]$ (colour). Dashed lines indicate decreased confidence in $\beta_{m \text {, unat }}$ because the assumption that no aerosols have reached a critical radius and become cloud condensation nuclei is unlikely to be met.

\subsection{Sensitivity of water vapour extinction coefficient to ceilometer central wavelength}

The sensitivity of water vapour extinction coefficient $C_{a b s, w v}$ to wavelength across the range $895-915 \mathrm{~m}$ can be high and it varies (Wiegner and Gasteiger, 2015). Water vapour absorption is low around the wavelength of $1064 \mathrm{~nm}$ so can be ignored for sensors operating lasers in that region. $C_{a b s, w v}$ for the default settings of the aerFO (section 2) is found to vary by a factor of two across the wavelength range 895 - $915 \mathrm{~nm}$ (not shown). However, as the sensitivity of $\beta_{m}$ to $C_{a b s, w v}$ is rather low, a maximum difference in $\beta_{m}$ of $6.3 \%$ is associated with the $C_{a b s, w v}$ values for the wavelength region tested. Again, if the specific central wavelength for each instrument (e.g. measured or manufacturer provided) was available to the aerFO, the uncertainty associated with water vapour absorption could be reduced (Wiegner and Gasteiger, 2015).

\section{Performance of aerFO on cloud-free days in 2015-2016}

Between 5 February 2015 - 31 December 2016 there were 11 entirely cloud-free days with more than one ALC in the LUMO network (Table 3) recording data. Of these, 4 are modelled using the Best scheme and 7 using MORUSES (section 3.3). The impact of the urban surface scheme is discussed (section 5.1) before analysing the general performance of aerFO on the cloud-free days (Sect. 5.2 and 5.3).

\subsection{Importance of surface scheme in estimating attenuated backscatter}

The aerFO can be used as a tool to explore implications of the change in MO urban surface scheme (section 3.3) on $\beta_{m}$ results. To demonstrate the use of the aerFO in this way, the difference between modelled and observed attenuated backscatter is compared along with sensible heat flux and other UKV model fields. Figure 9 shows a comparison between two spring cases (14 May 2015 and 04 May 2016), when the Best and MORUSES urban surface schemes were used respectively (section 3.3). Figure 10 shows the sensible heat flux $\left(Q_{H}\right)$ from the UKV for each grid cell that overlays a ceilometer site, and observed from KSSW (Figure 2), for both spring cases. From this case study comparison, it is evident that the mixing layer starts to grow $\sim 3 \mathrm{~h}$ later on the day simulated using the Best scheme (14 April 2015) compared to the MORUSES example (04 May 2016). Although several factors, including synoptic conditions, radiative forcing, and atmospheric stability are likely to explain some day-to-day variations in boundary layer dynamics, a systematic delay of the rise in turbulent sensible heat flux and in response morning transition onset is found for results obtained with the Best scheme in general (King, 2015) and was also the case on 14 April 2015 (Figure 10). The reduced vertical exchange predicted by the Best scheme is linked to a delayed increase of the modelled sensible heat flux $Q_{H, m}$. As a result, a strong positive bias $\left(\Delta \beta=\beta_{m}-\beta_{o}\right)$ near the surface (Figure 9c, left) persisting for the time with delayed mixing layer growth is usually detected for days modelled with 
Warren E, C Charlton-Perez, S Kotthaus, H Lean, S Ballard, E Hopkin, S Grimmond 2018 Evaluation of forward-modelled attenuated backscatter using an urban ceilometer network in London under clear-sky conditions Atmospheric Environment https://doi.org/10.1016/j.atmosenv.2018.04.045

the Best scheme. As reported by King (2015), the timing of turbulent mixing is clearly improved in the MORUSES scheme so that the positive morning bias in attenuated backscatter near the surface vanishes much earlier ( 0900) in the example shown (Figure 9i).

Given the importance of vertical mixing dynamics for the spatial distribution of scattering aerosols, the accuracy of turbulent processes represented in the surface scheme have direct influence on $\beta_{m}$ results. For the UKV, the comparison (Figure 9) suggests that the improvements of MORUSES compared to Best translate into a better agreement between modelled and observed attenuated backscatter.

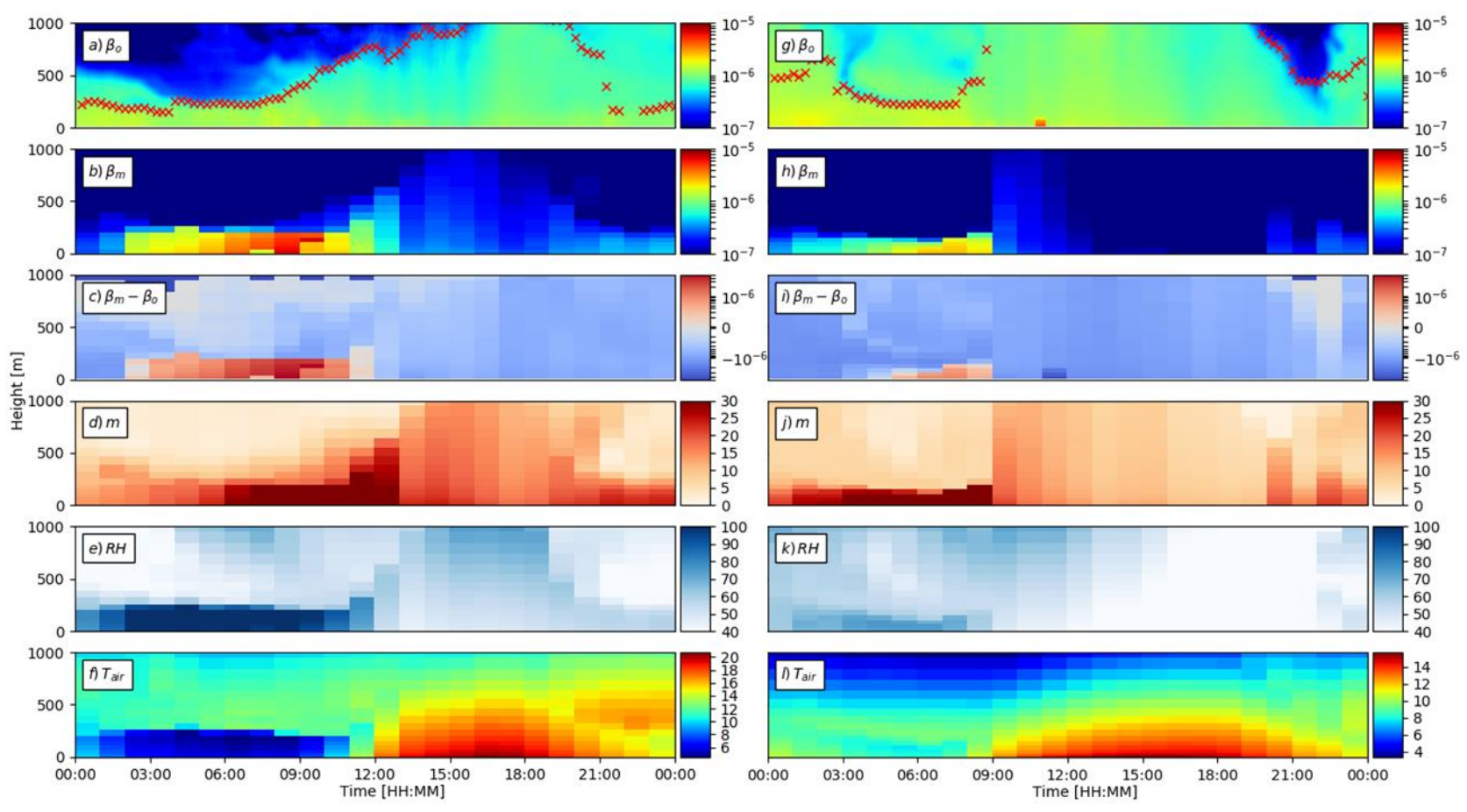

Figure 9: Vertical profiles of attenuated backscatter $\left[\mathrm{m}^{-1} \mathrm{sr}^{-1}\right]$ that are $(a, g)$ observed $\left(\beta_{o}\right)$ with estimated mixing layer height (red crosses, Kotthaus and Grimmond, 2018) and $(b, h)$ forward modelled $\left(\beta_{m}\right)$ using the aerFO (section 2).(c, i) Attenuated backscatter difference $\left(\beta_{m}-\beta_{o}\right)$ calculated using the hourly $\beta_{m}$ vertical profile and the vertical profile of $\beta_{o}$ nearest in time; $(d, j)$ aerosol mass mixing ratio $(m)\left[\mu \mathrm{g} \mathrm{kg}^{-1}\right] ;(e, k)$ relative humidity $(R H)[\%]$ and $(f, l)$ air temperature $\left(T_{a i r}\right)\left[{ }^{\circ} \mathrm{C}\right]$ at MR (Figure 2), with (a-e) 14 April 2015 using the Best urban surface scheme and (g-l) 04 May 2016 using the MORUSES urban surface scheme. Note that $(a, b, g, h)$ are plotted on a log scale and $(c, i)$ colour bar has a range of $\pm 5 \times 10^{-6} \mathrm{~m}^{-1}$ $s r^{-1}$ on a symmetric log scale.

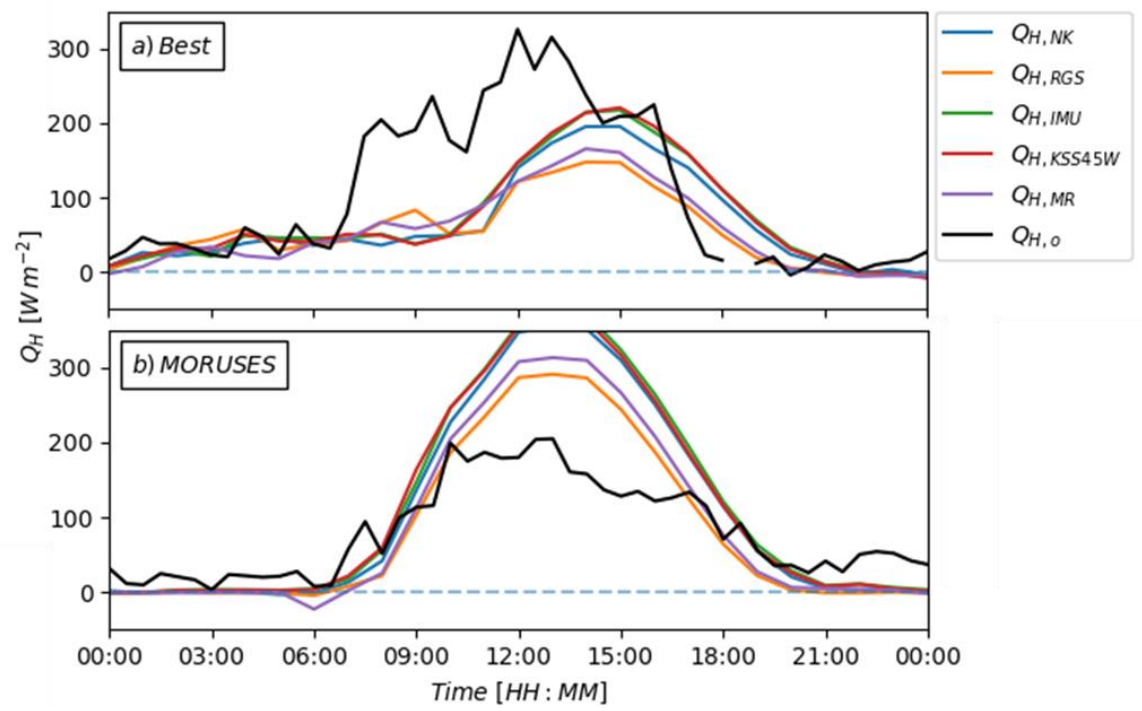

Figure 10: Modelled sensible heat flux $\left[\mathrm{W} \mathrm{m}^{-2}\right]$ from the UKV for the grid cells over each ceilometer site (Figure 2) and observed sensible heat flux at $K S S W\left(Q_{H, o}\right.$ black) from a CSAT3 sonic anemometer for: (a) 14 April 2015 (Best urban scheme) and (b) 04 May 2016 (MORUSES urban scheme). 


\subsection{Near-surface evaluation}

Near-surface data across the 11 cloud-free days are analysed $\left(\beta_{m}, \beta_{o}, m_{M U R K}\right.$ and $P M_{10}$, section 3.4). The data includes the in-situ $P M_{10}$ measurements and $m_{M U R K}$ taken at the nearest vertical model level to the $P M_{10}$ instrument height. $\beta_{o}$ is taken at the second range gate (section 3.1) and $\beta_{m}$ is selected at the model level closest to that height. Generally, $\beta_{m}$ is lower than $\beta_{o}\left(\operatorname{mean} \beta_{m} / \beta_{o}=0.53\right)$, and the variability of $\beta_{m} / \beta_{o}$ increases with increasing $m$ and $R H$ (see Figure S 2, supplementary materials).

Difference in UKV bulk aerosol mass mixing ratio and observed $P M_{10}(\Delta \mathrm{m})$ near the surface $(\sim 20 \mathrm{~m}$ range $)$ when compared to $\Delta \beta$ has a positive correlation (Figure 11, Spearman correlation coefficient $R=0.46$; Table 6 for collocated LAQN/LUMO sites NK and MR, Figure 2), and between $\Delta m$ and $\Delta \log 10(\beta)$ correlation is stronger (0.80). Assuming errors in modelled $R H$ are small and settings of the aerFO are appropriate, these statistically significant relations suggest that instances of $\Delta \beta$ and $\Delta \log 10(\beta)$ can be attributed to errors in

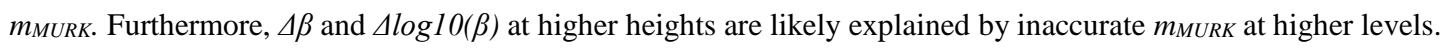

Comparing $\Delta m$ and $\Delta \beta$, the larger outliers are associated with particularly high model $R H\left(R H_{m}>\sim 90 \%\right)$. Given $\beta_{m}$ is very sensitive to $R H_{m}$ in humid conditions (section 4.4), any errors in $R H_{m}$ translate to errors in $\beta_{m}$ via errors in $f_{e x t, r h .}$. Hence, at high levels of $R H$ uncertainty in humidity can be the dominant factor in $\Delta \beta$ explaining the increased scatter in the relation between $\Delta \beta$ and $\Delta m$ and a weaker Spearman correlation coefficient $R$. If conditions of $R H_{m}>90 \%$ are excluded, the $\Delta \beta$ and $\Delta m$ correlation increases (Table 6). Excluding $R H_{m}>70 \%$ conditions increases $R$ to 0.58 . In addition, other aerFO assumptions may make $\beta_{m}$ inappropriate at high $R H$ leading to greater scatter. For example, $f_{e x t, r h}$ does not account for the activation of particles into cloud droplets and the continental aerosol aerFO lidar ratio is incompatible with cloud droplets. This supports the argument that under high $R H$, errors in $R H$ dominate $\Delta \beta$. However, the impact of sub-sampling at lower RH for $\Delta \log 10(\beta)$ makes little discernible difference.

Despite their statistically significant relation, some of $\Delta \beta\left(\right.$ and $\left.\Delta \log _{10}(\beta)\right)$ remains unexplained by $\Delta m$. Several aspects could play a role. One source of uncertainty lies in the observed $\beta_{o}$ in the near range where instrument-related artefacts (reported e.g. for CL31) introduce errors into the attenuated backscatter profiles. Although these artefacts are corrected on average, uncertainty remains (Kotthaus et al., 2016). Some uncertainty may also arise from using observed $P M_{10}$ to compare to $m_{M U R K}$. $P M_{10}$ measures the total

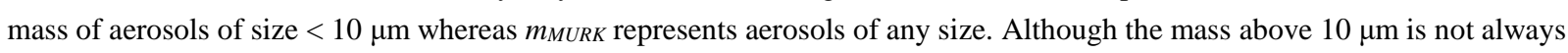
insignificant due to the presence of very coarse particles such as sea-salt, the number of particles above $10 \mu \mathrm{m}$ is often small (Figure 8.11 in Seinfeld and Pandis, 2016). Given aerFO is based on a series of assumptions regarding the composition of the bulk aerosol, errors will be introduced into $\beta_{m}$ if the aerosol proxy used does not sufficiently accurately represent the real atmospheric composition (both in terms of constituents and their relative proportions). Many other aerosol species may be present in London with variations at seasonal and hourly timescales (Young et al., 2015). Given that the complex index of refraction and hygroscopicity vary with aerosol species, inappropriate simplifications can cause errors in $Q_{e x t}$ (section 4.2).

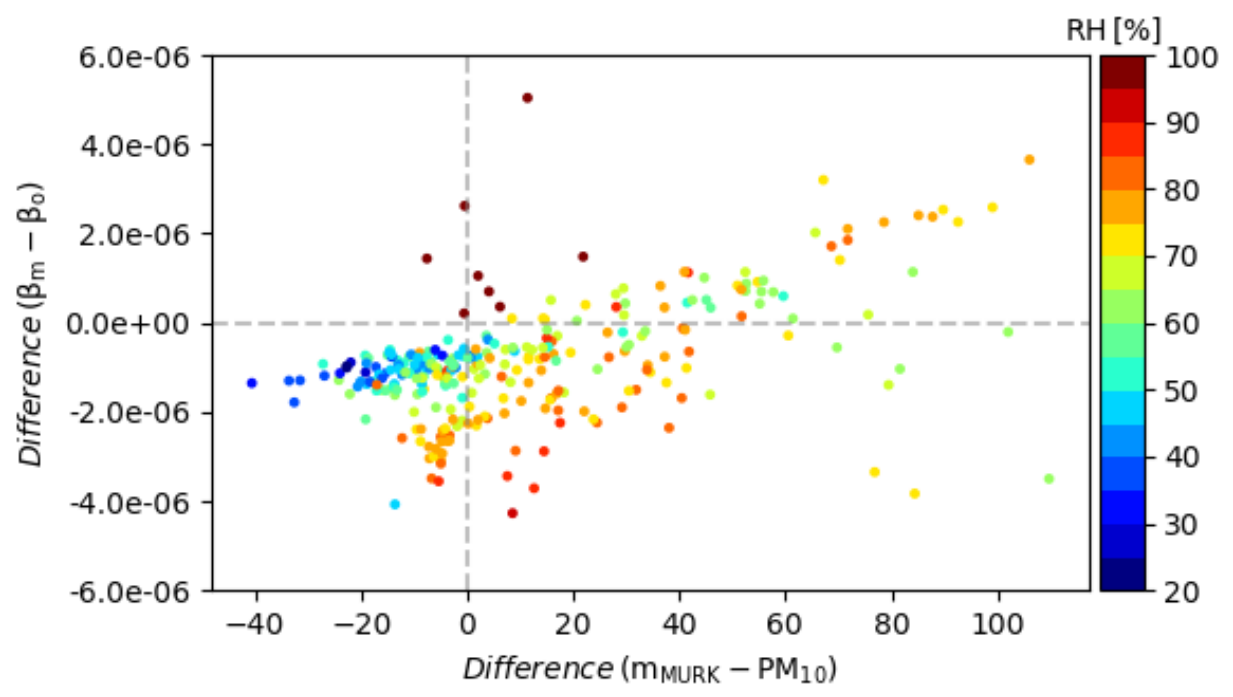

Figure 11: Hourly differences in aerosol mixing ratios (modelled $m_{M U R K}-$ observed $P M_{10}\left[\mu \mathrm{g} m^{-3}\right]$ ) versus differences in attenuated backscatter $\left(\triangle \beta=\beta_{m}\right.$ - $\beta_{o}\left[\mathrm{~m}^{-1} \mathrm{sr}^{-1}\right]$ ) at MR (Figure 2) with UKV relative humidity (colour) indicated. $\beta_{m}$ values for $21.7 \mathrm{~m}$ agl, which corresponds to the ALC's second range gate. $m_{M U R K}$ for $5 \mathrm{~m}$ agl which is closest to the $P M_{10}$ observation height. Nearest time of $\beta_{o}$ vertical profile is compared to each $\beta_{m}$ profile (288 profiles, from 12 days, Table 3 ). Spearman correlation coefficient $R=0.46$, $p$-value $>0.00$. 
Warren E, C Charlton-Perez, S Kotthaus, H Lean, S Ballard, E Hopkin, S Grimmond 2018 Evaluation of forward-modelled attenuated backscatter using an urban ceilometer network in London under clear-sky conditions Atmospheric Environment https://doi.org/10.1016/j.atmosenv.2018.04.045

Table 6: Spearman correlation coefficient $(R)$ of $\Delta \log _{10}(\beta)$ and $\Delta \beta$ against $\Delta m$, using different hourly sub-samples defined by model relative humidity $\left(R H_{m}\right)$.

\begin{tabular}{|c|c|c|c|}
\hline $\begin{array}{c}\text { Model RH range included } \\
{[\%]}\end{array}$ & $\begin{array}{c}\text { Sample size } \\
{[\text { hours] }}\end{array}$ & $\Delta \log _{10}(\beta)$ against $\Delta m$ & $\Delta \beta$ against $\Delta m$ \\
\cline { 3 - 4 } & 280 & 0.80 & 0.46 \\
\hline $0-100$ & 276 & 0.81 & 0.47 \\
\hline $0-90$ & 238 & 0.80 & 0.50 \\
\hline $0-80$ & 159 & 0.80 & 0.58 \\
\hline $0-70$ & 93 & 0.67 & 0.54 \\
\hline $0-60$ & 53 & 0.74 & 0.62 \\
\hline $0-50$ & 17 & 0.61 & 0.70 \\
\hline $0-40$ & & & \\
\hline
\end{tabular}

Figure 12 shows the absolute error in attenuated backscatter $\left(|\Delta \beta|=\left|\beta_{m}-\beta_{o}\right|\right)$ binned by $\Delta m .|\Delta \beta|$ tends to decrease with increasing $\Delta m$ between -50 and $75 \mu \mathrm{g} \mathrm{m}^{-3}$, and is likely compensating a bias in the aerFO. The aerFO attempts to only represent aerosol in the accumulation mode (Table 1) as it contains a large proportion of total aerosol mass. When $m_{M U R K}$ is high, this leads to higher estimates of $N$ and $r_{m d}$ in the aerFO, which in turn increases estimates of $\beta_{m}$. The higher $\beta_{m}$ estimates then compensate for the lack of coarse and fine mode aerosol representation in the aerFO. Consequently, future versions of the aerFO could improve estimates of $\beta_{m}$ if multiple modes of the aerosol distribution are represented more accurately through estimating $r_{m d}$ and $N$ individually.

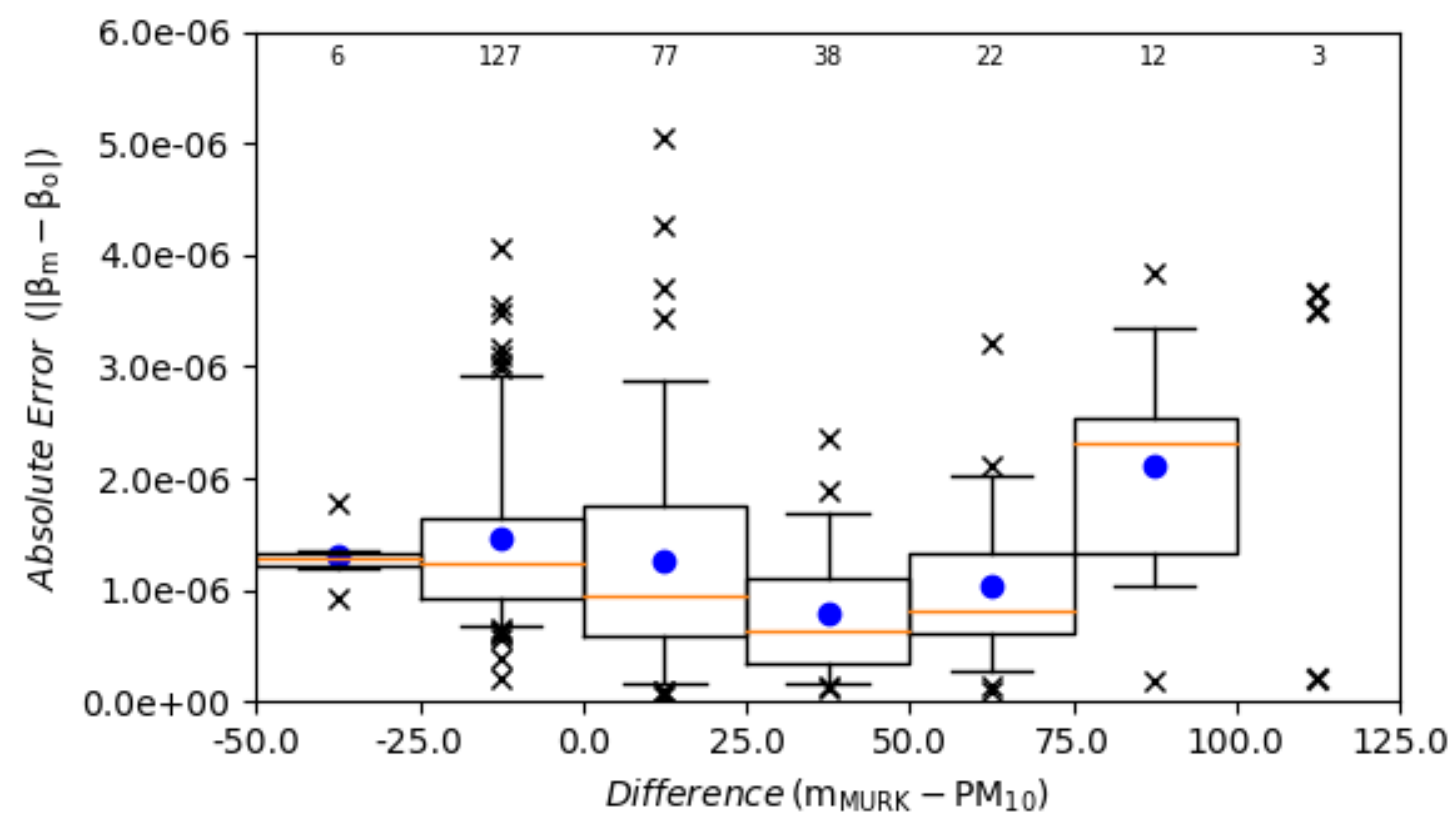

Figure 12: Absolute error in attenuated backscatter $\left(\left|\beta_{m}-\beta_{o}\right|\left[m^{-1} s^{-1}\right]\right)$ binned by difference in aerosol mixing ratios, $\left(\Delta m=\right.$ modelled $m_{M U R K}-$ observed $\left.P M_{10}\left[\mu \mathrm{g} \mathrm{m}^{-3}\right]\right)$ at MR (Figure 2). Bin size $=25 \mathrm{~kg} \mathrm{~m}^{-3}$. Sample means (blue circles), median (orange line) and inter-quartile range (box extent), and $5^{\text {th }}$ and $95^{\text {th }}$ percentiles (whiskers), statistical outliers (crosses) shown, with sample sizes above each boxplot. Same data samples used as in Figure 11. Boxplot omitted for $100<\Delta m \leq 125 \mu \mathrm{g} \mathrm{m}^{-3}$ due to the low sample size.

\subsection{Diurnal variation in agreement between integrated forward modelled attenuated backscatter and observed attenuated backscatter}

The differences in vertical profiles of $\beta_{m}$ and $\beta_{o}$ are assessed in order to identify whether consistent differences occur by time of day. Figure 13 shows the median and interquartile range of the absolute error $\left(\left|\beta_{m}-\beta_{o}\right|\right)$ at each site (Figure 2) by time of day. Four days are analysed when $\beta_{o}$ is available across all sites, from $73 \mathrm{~m}$ to $10 \%$ below the mixing layer height (estimated from MR

CL31observations, Kotthaus and Grimmond, 2018). This is to ensure that the same number of samples are used at each site despite different measurement heights (Table 3) but varies with mixing layer height growth/decay (Figure 13 numbers for each hour).

The variation in absolute error for each site is similar across the sites $\left(\sim 5 \times 10^{-7} \mathrm{~m}^{-1} \mathrm{sr}^{-1}\right)$. The generally higher absolute error values at KSS45W and RGS, with older generation hardware and software (Table 3), is likely explained by the higher noise levels and increased 
susceptibility to instrumental artefacts present in observed attenuated backscatter profiles (section 3.1 in Kotthaus et al., 2016). The higher noise and effect of instrumental artefacts in older instrument results also reduced Spearman correlation coefficients (not shown).

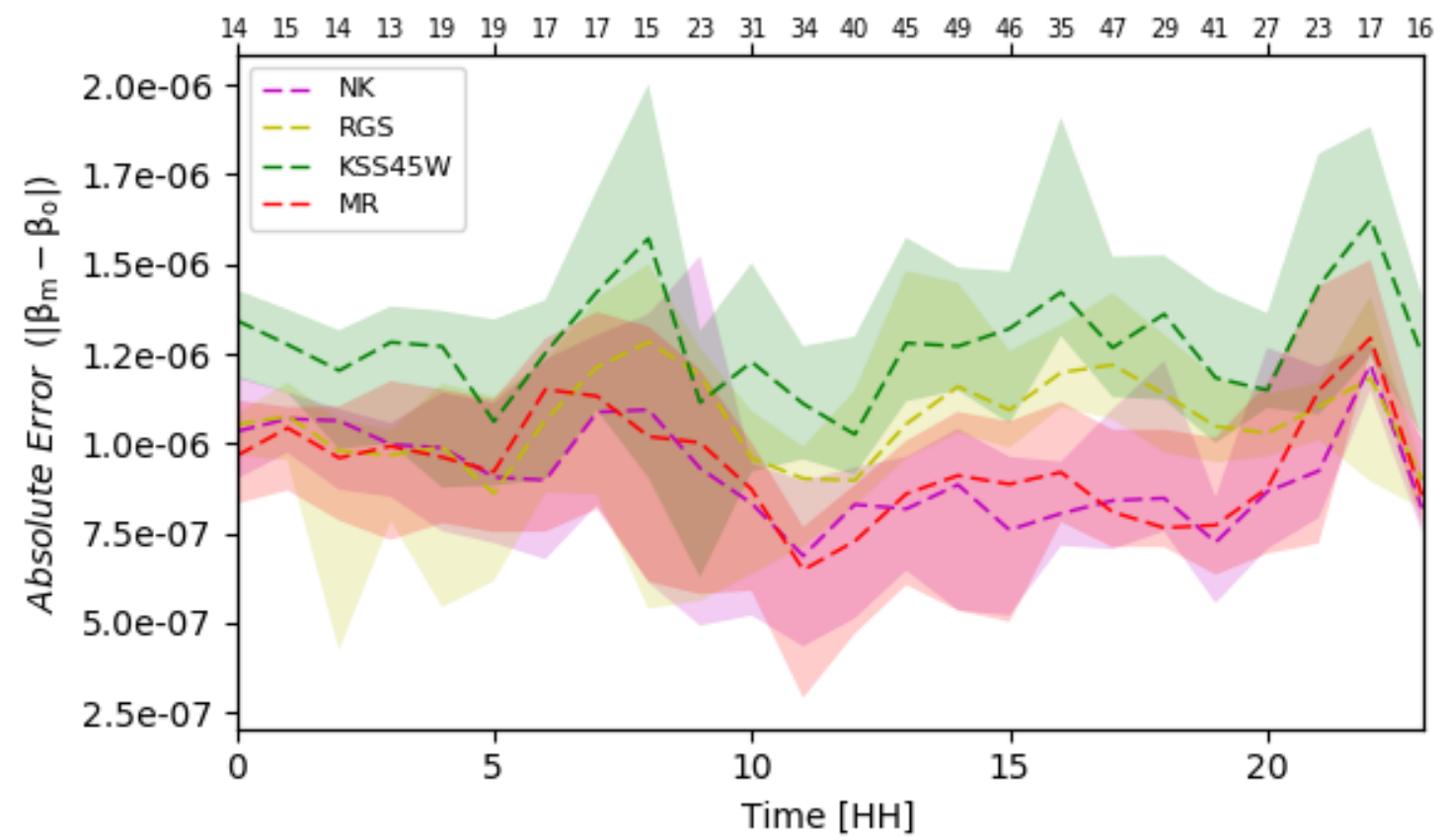

Figure 13: Hourly median (dashed) and IQR (shading) of the absolute error $\left|\beta_{\mathrm{m}}-\beta_{o}\right|$ at five ALC sites (Figure 2), calculated for four cloud-free sample days $\left(14,15,21\right.$ April 2015 and 19 January 2016), using hourly $\beta_{\mathrm{m}}$ vertical profiles and the vertical profile of $\beta_{\mathrm{o}}$ nearest in time. Profiles of $\beta_{m}$ and $\beta_{\mathrm{o}}$ were compared between $73 \mathrm{~m}$ and $10 \%$ below the top of the mixing layer height estimated from Vaisala CL31 observations at MR (Kotthaus and Grimmond, 2018). Sample size for each hourly composite bin are shown above each hour. Note: sample sizes are the same for each site and are lower when the mixing layer height was lower in the early morning, late evening.

\section{Conclusions}

The aerosol lidar forward operator (aerFO) developed (section 2) to estimate attenuated backscatter $\left(\beta_{m}\right)$ for cloud-free conditions, when aerosols are the dominant scatterers, is evaluated in an urban setting. The aerFO requires numerical weather prediction (NWP) model forecast as input. Besides the aerosol field, relative humidity $(R H)$ is required. If only a bulk aerosol mass mixing ratio $(m)$ is available from NWP, the aerFO includes estimates of species-specific properties based on aerosol composition assumptions. Here, $m_{M U R K}$ and $R H$ taken from the Met Office UKV $(1.5 \mathrm{~km})$ is used to explore the aerFO and applications.

Assumptions within the aerFO are assessed based on sensitivity studies. The choice of radius range used to calculate $N_{0}$ is critical given the sensitivity of $\beta_{m}$ to number concentration $N$. Use of observed aerosol distribution data could allow more appropriate values for $N_{0}$ to be determined and reduce the uncertainty in $\beta_{m}$. There are differences in both the dry extinction efficiency $\left(Q_{e x t, d r y}\right)$ and the extinction enhancement factor $\left(f_{e x t, r h}\right)$ for commonly observed urban constituents. Notably, black carbon has very distinct signatures caused by its high absorptivity, low scattering properties, hygroscopicity and physical particle growth. Consequently, accuracy of $\beta_{m}$ can be improved by providing aerFO with more accurate aerosol species composition and proportions of the bulk aerosol quantity. If atmospheric constituents are significantly different to those assumed, biases could be inadvertently introduced when assimilating $\beta_{o}$.

Different automatic lidars and ceilometers (ALC) have different laser central wavelengths plus uncertainty (e.g. for Vaisala CL31, available specifications are rather vague $905 \pm 10 \mathrm{~nm}$ ). The impact of varying wavelength on estimated optical properties is explored. The sensitivity of $f_{\text {ext, }, \text { rh }}$ to wavelength for the wavelength range $895-915 \mathrm{~nm}$ (i.e. common for Vaisala ALC) is small $(<1.5 \%)$. However, for some aerosol species $Q_{e x t, d r y}$ is clearly affected by uncertainties in laser wavelength ( $\sim 8 \%$ for ammonium sulphate and ammonium nitrate). The mass absorption of water vapour is found to vary by a factor of two across this wavelength range, translating into an uncertainty in $\beta_{m}$ of $6.3 \%$. Hence, given spectral variations of absorption and extinction even small variations in laser wavelength can be important in this region. If the centre laser wavelength can be specified more accurately in the aerFO settings (e.g. than Vaisala CL31 rather vague $905 \pm 10 \mathrm{~nm}$ ) such variations in $Q_{e x t, d r y}$ could be accounted for by the aerFO. Manufacturers are encouraged to release this information for each instrument, to permit more accurate estimates of the various wavelength related 
variables, including water vapour absorption.

Comparing results for the two most common ALC wavelengths, i.e. $905 \mathrm{~nm}$ (e.g. Vaisala) and $1064 \mathrm{~nm}$ (e.g. Lufft) reveals large differences in both $Q_{e x t, d r y}$ and $f_{e x t, r h}$. Therefore, different look up tables of aerFO should be used for different laser wavelengths.

Sensitivity studies of unattenuated backscatter $\left(\beta_{m, \text { unatt }}\right)$ to aerFO inputs of $m$ and $R H$ allow attribution from their inaccuracies to be assessed. $\beta_{m \text {,unatt }}$ is sensitive to $m$ with a weak exponential relation that increases with increasing $m$. Overall, $R H$ has a relatively weaker relation with $\beta_{m}$ than with $m$. However, there is a stronger exponential relation between $R H$ and $\beta_{m \text {,unatt }}$ at high $R H$ values (> 60\%) caused by the exponential growth of particles parameterised by $f_{e x t, r h}$. This suggests that $R H$ becomes increasingly important for the accurate estimation of $\beta_{m}$ as $R H$ increases. Therefore, the impact of errors in $R H$ will increase.

Implications of a change in UKV urban surface scheme from the Best to MORUSES is explored based on two spring case study days. The mean bias error $\left(\Delta \beta=\beta_{m}-\beta_{o}\right.$ ) is positive during morning hours at heights below $\sim 250 \mathrm{~m}$ for the day modelled using the Best scheme. This is partially due to the delayed vertical mixing linked to a delayed morning increase of modelled sensible heat flux $\left(Q_{H}\right)$ (noted previously for this surface scheme). The delay in vertical mixing limits near-surface NWP aerosol dispersion. With an improved $Q_{H}$ timing with MORUSES, the bias in $\Delta \beta$ is reduced less in the morning below $\sim 250 \mathrm{~m}$. This highlights the importance of the mixing dynamics within the NWP model to accurately distribute aerosols within the boundary layer and hence obtain representative $\beta_{m}$ results.

Comparison of $\beta_{m} / \beta_{o}$ to $R H$ with respect to $m_{M U R K}$ shows that $\beta_{m}$ is often less than $\beta_{o}$ (mean $\beta_{m} / \beta_{o}=0.53$ ). The variation in $\beta_{m} / \beta_{o}$ depends upon the magnitudes and errors of $m$ and $R H$. Analysis of the relation between $\Delta m\left(=m_{M U R K}-P M_{10}\right)$ and $\Delta \beta$ found that a positive, statistically significant Spearman correlation exists $(R=0.46)$, which increases when restricted to periods with lower $R H$ values. The correlation between $\Delta \log _{10}(\beta)$ was larger $(R=0.80)$ but does not increase when restricted to periods with lower $R H$. Hence, assimilation of $\beta_{o}$ into NWP models is expected to have an increasingly effective contribution when atmospheric conditions are drier. The aerFO is still effective at high $R H$ values, despite potentially violating the assumption that the cloud droplets have not yet formed. This could be because $f_{\text {ext, } r h}$ is representing well the exponential growth in particle radii at high $R H$ values. A specific parameterisation to incorporate cloud droplets at high RH values would broaden the applicability of the aerFO to instances of near saturation. The absolute error $\left(\left|\beta_{m}-\beta_{o}\right|\right)$ between vertical profiles of $\beta_{m}$ and $\beta_{o}$ show a dependence on noise levels within the observations. Quality of attenuated backscatter measurements can be improved by operating recent hardware, using the most appropriate firmware version and settings, and ensuring careful maintenance (e.g. window cleaning). This finding highlights the need for careful processing of ALC measurements prior to use in model evaluation or data assimilation. Furthermore, detailed knowledge of sensor characteristics can provide useful insights for interpretation.

As boundary layer dynamics are critical for vertical distribution of aerosol, data assimilation of the entire $\beta_{o}$ profile would have a limited effect if the aerosol is a passive tracer that is one-way coupled with model dynamics such as the UKV MURK. However, to account for a potential general bias affecting the whole aerosol profile, an integrated value of $\beta_{o}$ could be assimilated.

The bulk aerosol composition is important in accurately estimating the extinction efficiency $\left(Q_{e x t}\right)$ and therefore $\beta_{m}$. Performance of the aerFO depends on the level of detail provided by the aerosol field(s) available from the NWP model. Some models contain information on various aerosol species, e.g. the AQUM configuration of the MO Unified model (Savage et al., 2013), but such models usually still run at lower spatial resolution. The high spatial resolution (grid $\leq 1.5 \mathrm{~km}$ ) MO models (e.g. UKV or MO London model) enable a more detailed representation of the high spatial heterogeneity of urban areas. However, these usually have very simple aerosol schemes (e.g. passive tracer $\left.m_{M U R K}\right)$.

The current default for aerFO includes a constant lidar ratio representative of continental aerosol. Given the importance of this parameter, a more dynamic approach accounting for variable aerosol composition could significantly improve results. However, this can be challenging in urban settings where the relative contribution of various aerosol types is often highly variable due to the complex mixture of local sources and long-range transport. Still, the amount of aerosol and its composition can be distinct in an urban area when compared to the surroundings; therefore, a speciated lidar ratio would be more suitable. For example, urban areas tend to have higher proportions of black carbon, which has very specific aerosol properties.

The aerFO has demonstrated utility as a tool to evaluate vertical profiles of aerosol bulk mass mixing ratio and RH from NWP models. Its results can also be used in conjunction with meteorological observations to explore processes related to near-surface aerosol mass variability or horizontal advection of air masses. Given aerosol is a tracer for boundary layer dynamics, application of the aerFO has proven very useful to evaluate the performance of urban surface parameterisation schemes and their ability to drive growth of the 
Warren E, C Charlton-Perez, S Kotthaus, H Lean, S Ballard, E Hopkin, S Grimmond 2018 Evaluation of forward-modelled attenuated backscatter using an urban ceilometer network in London under clear-sky conditions Atmospheric Environment https://doi.org/10.1016/j.atmosenv.2018.04.045

mixing layer.

\section{Acknowledgements}

EW was funded by the NERC Scenario DTP and University of Reading. The LUMO instruments and measurements have been funded by NERC AirPro, NERC ClearfLo, EUf7 BRIDGE and EUf7 emBRACE, H2020 URBANFLUXES, Met Office/Newton Fund CSSPChina, KCL, and University of Reading. Sites are provided by Royal Geographical Society (with IBG), King's College London, and Islington council. $P M_{10}$ data are provided by KCL Environmental Research Group (ERG)/London Air Quality Network (LAQN). Helpful discussions were had with Peter Clark, Jim Haywood, Lucy Neal, Bernard Claxton, Claire Ryder, Nicholas Bellouin, Ben Johnson, James Manners, Stephen Havemann, Joelle Buxmann, Ewan O'Conner, Anthony Illingworth, and Helen Dacre. Helpful comments on the manuscript were made by Sylvia Bohnenstengel. We would also like to acknowledge the invaluable discussions within the TOPROF community (European Cooperation in Science and Technology (COST) action: ES1303). The authors are grateful to Will Morrison, Kjell zum Berge, Christoph Kent, Andy Gabey, Izzy Capel-Timms, David Meyer, Ben Crawford and the many others who maintain the LUMO operations.

\section{8. $\quad$ References}

Ansmann, A., Tesche, M., Groß, S., Freudenthaler, V., Seifert, P., Hiebsch, A., Schmidt, J., Wandinger, U., Mattis, I., Müller, D., Wiegner, M., 2010. The 16 April 2010 major volcanic ash plume over central Europe: EARLINET lidar and AERONET photometer observations at Leipzig and Munich, Germany. Geophys. Res. Lett. $37,1-5$. https://doi.org/10.1029/2010GL043809

Aptowicz, K.B., Pinnick, R.G., Hill, S.C., Pan, Y.L., Chang, R.K., 2006. Optical scattering patterns from single urban aerosol particles at Adelphi, Maryland, USA: A classification relating to particle morphologies. J. Geophys. Res. Atmos. 111, 1-13. https://doi.org/10.1029/2005JD006774

AQEG, 2005. Particulate Matter in the United Kingdom. DEFRA, London, UK.

Atkinson, R.W., Kang, S., Anderson, H.R., Mills, I.C., Walton, H.A., 2014. Epidemiological time series studies of PM 2.5 and daily mortality and hospital admissions: a systematic review and meta-analysis. Thorax 69, 660-665. https://doi.org/10.1136/thoraxjnl-2013-204492

Benedetti, A., Dabas, A., 2016. Assessment of the necessary developments to assimilate Aeolus and EarthCARE aerosol profile products, Technical Note 1 of ESA contract number 4000116106

Benedetti, A., Morcrette, J.-J., Boucher, O., Dethof, A., Engelen, R.J., Fisher, M., Flentje, H., Huneeus, N., Jones, L., Kaiser, J.W., Kinne, S., Mangold, A., Razinger, M., Simmons, A.J., Suttie, M., 2009. Aerosol analysis and forecast in the European Centre for Medium-Range Weather Forecasts Integrated Forecast System: 2. Data assimilation. J. Geophys. Res. 114, D13205. https://doi.org/10.1029/2008JD011115

Best, M.J., 1998. A Model to Predict Surface Temperatures. Boundary-Layer Meteorol. 88, 279-306. https://doi.org/10.1023/A:1001151927113

Best, M.J., Pryor, M., Clark, D.B., Rooney, G.G., Essery, R.. L.H., Ménard, C.B., Edwards, J.M., Hendry, M.A., Porson, A., Gedney, N., Mercado, L.M., Sitch, S., Blyth, E., Boucher, O., Cox, P.M., Grimmond, C.S.B., Harding, R.J., 2011. The Joint UK Land Environment Simulator (JULES), model description - Part 1: Energy and water fluxes. Geosci. Model Dev. 4, 677-699. https://doi.org/10.5194/gmd-4-677-2011

Bohnenstengel, S.I., Belcher, S.E., Aiken, A., Allan, J.D., Allen, G., Bacak, A., Bannan, T.J., Barlow, J.F., Beddddows, D.C.S., Blossss, W.J., Booth, A.M., Chemel, C., Coceal, O., Di Marco, C.F., Dubey, M.K., Faloon, K.H., Flemiming, Z.L., Furger, M., Gietl, J.K., Graves, R.R., Green, D.C., Grimmimmimmond, C.S.B., Halios, C.H., Hamiamiamilton, J.F., Harrisison, R.M., Heal, M.R., Heard, D.E., Helfter, C., Herndon, S.C., Holmes, R.E., Hopkins, J.R., Jones, A.M., Kelly, F.J., Kotthaus, S., Langford, B., Lee, J.D., Leigh, R.J., Lewisis, A.C., Lidsidsidster, R.T., Lopez-Hilfiker, F.D., McQuaidaid, J.B., Mohr, C., Monks, P.S., Nemimitz, E., Ng, N.L., Percival, C.J., Prévôt, A.S.H., Ricketts, H.M.A., Sokhi, R., Stone, D., Thornton, J.A., Tremper, A.H., Valach, A.C., Vissississer, S., Whalley, L.K., Williamsiamsiamsiams, L.R., Xu, L., Young, D.E., Zotter, P., 2015a. Supplement Meteorology, Air Quality, and Health in London: The ClearfLo Project. Bull. Am. Meteorol. Soc. 87-95. https://doi.org/10.1175/BAMS-D-12-00245.2

Bohnenstengel, S.I., Belcher, S.E., Aiken, A., Allan, J.D., Allen, G., Bacak, A., Bannan, T.J., Barlow, J.F., Beddddows, D.C.S., Blossss, W.J., Booth, A.M., Chemel, C., Coceal, O., Di Marco, C.F., Dubey, M.K., Faloon, K.H., Flemiming, Z.L., Furger, M., Gietl, J.K., Graves, R.R., Green, D.C., Grimmond, C.S.B., Halios, C.H., Hamiamiamilton, J.F., Harrisison, R.M., Heal, M.R., Heard, D.E., Helfter, C., Herndon, S.C., Holmes, R.E., Hopkins, J.R., Jones, A.M., Kelly, F.J., Kotthaus, S., Langford, B., Lee, J.D., Leigh, R.J., Lewisis, A.C., Lidsidsidster, R.T., Lopez-Hilfiker, F.D., McQuaidaid, J.B., Mohr, C., Monks, P.S., Nemimitz, E., Ng, N.L., Percival, C.J., Prévôt, A.S.H., Ricketts, H.M.A., Sokhi, R., Stone, D., Thornton, J.A., Tremper, A.H., Valach, A.C., Vissississer, S., Whalley, L.K., Williamsiamsiamsiams, L.R., Xu, L., Young, D.E., Zotter, P., 2015b. Meteorology, air quality, and health in London: The ClearfLo project. Bull. Am. Meteorol. Soc. 96, 779-804. https://doi.org/10.1175/BAMS-D-12-00245.1

Bohnenstengel, S.I., Evans, S., Clark, P.A., Belcher, S.E., 2011. Simulations of the London urban heat island. Q. J. R. Meteorol. Soc. 137, 1625-1640. https://doi.org/10.1002/qj.855

Boucher, O., Randall, D., Artaxo, P., Bretherton, C., Feingold, G., Forster, P., Kerminen, V.-M.V.-M., Kondo, Y., Liao, H., Lohmann, U., Rasch, P., Satheesh, S.K., Sherwood, S., Stevens, B., Zhang, X.Y., Zhan, X.Y., 2013. Clouds and Aerosols. Clim. Chang. 2013 Phys. Sci. Basis. Contrib. Work. Gr. I to Fifth Assess. Rep. Intergov. Panel Clim. Chang. 571-657. https://doi.org/10.1017/СBO9781107415324.016

Boyouk, N., Léon, J.-F., Delbarre, H., Augustin, P., Fourmentin, M., 2011. Impact of sea breeze on vertical structure of aerosol optical properties in Dunkerque, France. Atmos. Res. 101, 902-910. https://doi.org/10.1016/j.atmosres.2011.05.016

Chan, K.L., Wiegner, M., Flentje, H., Mattis, I., Wagner, F., Gasteiger, J., Geiß, A., 2016. Simulation of ceilometer backscatter signal from global chemical transport model data, in: 2016-12-01 SWG 1.4: O-B Analysis for Ceilometers. Paris, France.

Charlton-Perez, C., O'Connor, E., Ballard, S., Adam, M., Klugmann, D., Cox, O., 2015. Review of ceilometer operator design. Met Office.

Charlton-Perez, C., Simonin, D., Ballard, S., Hopkin, E., Illingworth, A., Kotthaus, S., Westbrook, C., Grimmond, C.S.B., 2016. Suitability of Ceilometer Observations for DA, Data Assimilation and Ensembles Science Report 10. Met Office.

Chen, C.H., Chan, C.C., Chen, B.Y., Cheng, T.J., Leon Guo, Y., 2015. Effects of particulate air pollution and ozone on lung function in non-asthmatic children. Environ. Res. 137, 40-48. https://doi.org/10.1016/j.envres.2014.11.021

Chudnovsky, a., Lyapustin, a., Wang, Y., Tang, C., Schwartz, J., Koutrakis, P., 2013. High resolution aerosol data from MODIS satellite for urban air quality studies. Cent. Eur. J. Geosci. 6, 17-26. https://doi.org/10.2478/s13533-012-0145-4

Clark, P.A., Harcourt, S.A., Macpherson, B., Mathinson, C.T., Cusak, S., Naylor, M., 2008. Prediction of visibility and aerosol within the operational Met Office Unified Model. I: Model formulation and variational assimilation. Q. J. R. Meteorol. Soc. 134, 1801-1816. https://doi.org/10.1002/qj

Claxton, B.M., 2013. Parameters controlling the aerosol hydration scheme within the UKV visibility parametrization. Met Off. Cardingt. Tech. Note No. 85 1-35.

Clough, S.A., lacono, M.J., Moncet, J.-L., 1992. Line-by-line calculations of atmospheric fluxes and cooling rates: Application to water vapor. J. Geophys. Res. $97,15761$. https://doi.org/10.1029/92JD01419

Clough, S.A., Shephard, M.W., Mlawer, E.J., Delamere, J.S., lacono, M.J., Cady-Pereira, K., Boukabara, S., Brown, P.D., 2005. Atmospheric radiative transfer modeling: A summary of the AER codes. J. Quant. Spectrosc. Radiat. Transf. 91, 233-244. https://doi.org/10.1016/j.jqsrt.2004.05.058

Dawson, K.W., Meskhidze, N., Josset, D., Gassó, S., 2015. Spaceborne observations of the lidar ratio of marine aerosols. Atmos. Chem. Phys. 15, 3241-3255. https://doi.org/10.5194/acp-15-3241-2015

DEFRA, 2016. National Atmospheric Emissions Inventory [WWW Document]. URL http://naei.defra.gov.uk/about/index (accessed 11.10.16).

Doherty, S.J., Anderson, T.L., Charlson, R.J., 1999. Measurement of the lidar ratio for atmospheric aerosols with a $180^{\circ}$ Backscatter Nephelometer. Most 38. 
Warren E, C Charlton-Perez, S Kotthaus, H Lean, S Ballard, E Hopkin, S Grimmond 2018 Evaluation of forward-modelled attenuated backscatter using an urban ceilometer network in London under clear-sky conditions Atmospheric Environment https://doi.org/10.1016/j.atmosenv.2018.04.045

Edwards, J.M., Slingo, A., 1996. Studies with a flexible new radiation code. I: Choosing a configuration for a large-scale model. Q. J. R. Meteorol. Soc. 122, 689-719. https://doi.org/10.1002/qj.49712253107

EEA, 2015. Air quality in Europe-2015 report. https://doi.org/10.2800/62459

Elliot, A.J., Smith, S., Dobney, A., Thornes, J., Smith, G.E., Vardoulakis, S., 2016. Monitoring the effect of air pollution episodes on health care consultations and ambulance call-outs in England during March/April 2014: A retrospective observational analysis. Environ. Pollut. 214, 903-911. https://doi.org/10.1016/j.envpol.2016.04.026

Emeis, S., 2011. Surface-Based Remote Sensing of the Atmospheric Boundary Layer, Atmospheric and Oceanographic Sciences Library. Springer Netherlands, Dordrecht. https://doi.org/10.1007/978-90-481-9340-0

Fitzgerald, J.W., 1975. Approximation Formulas for the Equilibrium Size of an Aerosol Particle as a Function of Its Dry Size and Composition and the Ambient Relative Humidity. J. Appl. Meteorol. 14, 1044-1049. https://doi.org/10.1175/1520-0450(1975)014<1044:AFFTES>2.0.CO;2

Flentje, H., Claude, H., Elste, T., Gilge, S., Köhler, U., Plass-Dülmer, C., Steinbrecht, W., Thomas, W., Werner, A., Fricke, W., 2010a. The Eyjafjallajökull eruption in April 2010 - Detection of volcanic plume using in-situ measurements, ozone sondes and lidar-ceilometer profiles. Atmos. Chem. Phys. 10, 10085-10092. https://doi.org/10.5194/acp-10-10085-2010

Flentje, H., Heese, B., Reichardt, J., Thomas, W., 2010b. Atmospheric Measurement Techniques Discussions Aerosol profiling using the ceilometer network of the German Meteorological Service. Atmos. Meas. Tech. Discuss 3, 3643-3673. https://doi.org/10.5194/amtd-3-3643-2010

Flynn, C., 2004. Vaisala ceilometer (model CT25K) handbook, Vaisala.

Forster, P., Ramaswamy, V., Artaxo, P., Berntsen, T., Betts, R., Fahey, D.W., Haywood, J., Lean, J., Lowe, D.C., Myhre, G., Nganga, J., Prinn, R., Raga, G., Schultz, M., Van Dorland, R., 2007. Changes in atmospheric constituents and in radiative forcing. Cambridge University Press, Cambridge, United Kingdom.

Francis, P.N., 2012. The direct assimilation of surface cloud reports in the UKV model. Satellite Applications Technical Memo 9, Met Office.

Geisinger, A., Behrendt, A., Wulfmeyer, V., Strohbach, J., Förstner, J., Potthast, R., 2017. Development and Application of a Backscatter Lidar Forward Operator for Quantitative Validation of Aerosol Dispersion Models and Future Data Assimilation. Atmos. Meas. Tech. Discuss. https://doi.org/10.5194/amt-2017-142

Gosse, S.F., Wang, M., Labrie, D., Chylek, P., 1997. Imaginary part of the refractive index of sulfates and nitrates in the 0.7-2.6-micron spectral region. Appl. Opt. 36, 36223634

Goto, D., Badarinath, K.V.S., Takemura, T., Nakajima, T., 2011. Simulation of aerosol optical properties over a tropical urban site in India using a global model and its comparison with ground measurements. Ann. Geophys. 29, 955-963. https://doi.org/10.5194/angeo-29-955-2011

Grell, G.A., Knoche, R., Peckham, S.E., McKeen, S.A., 2004. Online versus offline air quality modeling on cloud-resolving scales. Geophys. Res. Lett. 31, 6-9. https://doi.org/10.1029/2004GL020175

Haeffelin, M., Laffineur, Q., Bravo-Aranda, J.A., Drouin, M.A., Casquero-Vera, J.A., Dupont, J.C., De Backer, H., 2016. Radiation fog formation alerts using attenuated backscatter power from automatic lidars and ceilometers. Atmos. Meas. Tech. 9, 5347-5365. https://doi.org/10.5194/amt-9-5347-2016

Harrison, R.M., Dall'Osto, M., Beddows, D.C.S., Thorpe, A.J., Bloss, W.J., Allan, J.D., Coe, H., Dorsey, J.R., Gallagher, M., Martin, C., Whitehead, J., Williams, P.I., Jones, R.L., Langridge, J.M., Benton, A.K., Ball, S.M., Langford, B., Hewitt, C.N., Davison, B., Martin, D., Petersson, K.F., Henshaw, S.J., White, I.R., Shallcross, D.E., Barlow, J.F., Dunbar, T., Davies, F., Nemitz, E., Phillips, G.J., Helfter, C., Di Marco, C.F., Smith, S., 2012. Atmospheric chemistry and physics in the atmosphere of a developed megacity (London): An overview of the REPARTEE experiment and its conclusions. Atmos. Chem. Phys. 12, 3065-3114. https://doi.org/10.5194/acp-12-3065-2012 Haywood, J., Boucher, O., 2000. Estimates of the Direct and Indirect Radiative Forcing Due To Tropospheric Aerosols : a Review 38, 513-543.

Haywood, J., Bush, M., Abel, S., Claxton, B., Coe, H., Crosier, J., Harrison, M., Macpherson, B., Naylor, M., Osborne, S., 2008. Prediction of visibility and aerosol within the operational Met Office Unified Model. II: Validation of model performance using observational data. Q. J. R. Meteorol. Soc. 134, 1817-1832. https://doi.org/10.1002/qj.275

Haywood, J., Osborne, S.R., Francis, P.N., Keil, A., Formenti, P., Andreae, M.O., Kaye, P.H., 2003. The mean physical and optical properties of regional haze dominated by biomass burning aerosol measured from the C-130 aircraft during SAFARI 2000. J. Geophys. Res. 108, 8473. https://doi.org/10.1029/2002jd002226

Hopkin, E., Illingworth, A., Charlton-Perez, C., Westbrook, C., Ballard, S., 2017. Calibration of the Met Office Ceilometer Network using the Cloud Method. EMS Annu. Meet Abstr. 14.

Hopkin, E., Illingworth, A., Charlton-Perez, C., Westbrook, C., Ballard, S., n.d. A robust automated technique for operational calibration of ceilometers using integrated backscatter from totally attenuating liquid cloud. In preparation.

Jacobson, M.Z., 2005. Fundamentals of Atmospheric Modeling, 2nd Editio. ed. Cambridge University Press, Cambridge, UK.

Janisková, M., Mahfouf, J.-F., Morcrette, J.-J., 2002. Preliminary studies on the variational assimilation of cloud-radiation observations. Q. J. R. Meteorol. Soc. 128, 27132736. https://doi.org/10.1256/qj.01.192

Janisková, M., Stiller, O., 2010. Development of strategies for radar and lidar data assimilation. Reading, UK.

Janisková, M., Stiller, O., Michele, S. Di, Forbes, R., Morcrette, J., Ahlgrimm, M., Bauer, P., 2010. QuARL - Quantitative Assessment of the Operational Value of Space-Borne Radar and Lidar Measurements of Cloud and Aerosol Profiles. ESA Contract Report.

Ji, D., Li, L., Pang, B., Xue, P., Wang, L., Wu, Y., Zhang, H., Wang, Y., 2017. Characterization of black carbon in an urban-rural fringe area of Beijing. Environ. Pollut. 223, 524534. https://doi.org/10.1016/j.envpol.2017.01.055

Jin, Y., Kai, K., Kawai, K., Nagai, T., Sakai, T., Yamazaki, A., Uchiyama, A., Batdorj, D., Sugimoto, N., Nishizawa, T., 2015. Ceilometer calibration for retrieval of aerosol optical properties. J. Quant. Spectrosc. Radiat. Transf. 153, 49-56. https://doi.org/10.1016/j.jqsrt.2014.10.009

Jose, S., Niranjan, K., Gharai, B., Rao, P.V.N., Nair, V.S., 2016. Characterisation of Absorbing Aerosols Using Ground and Satellite Data at an Urban Location, Hyderabad. Aerosol Air Qual. Res. 16, 1427-1440. https://doi.org/10.4209/aaqr.2014.09.0220

King's College London, 2016. Air quality networks - beyond compliance assessment [WWW Document]. URL http://www.kcl.ac.uk/lsm/research/divisions/aes/research/ERG/measurement/air-quality-networks/index.aspx (accessed 8.25.16).

King, R., 2015. Comparison of UKV with MORUSES and JULES in Urban Areas, Met Office. Met Office.

Kotthaus, S., Grimmond, C.S.B., 2018. Atmospheric Boundary Layer Characteristics from Ceilometer Measurements, Part 2: Application to London's Urban Boundary Layer. Q. J. R. Meteorol. Soc. https://doi.org/10.1002/qj.3298

Kotthaus, S., Grimmond, C.S.B., 2014. Energy exchange in a dense urban environment - Part I: Temporal variability of long-term observations in central London. Urban Clim. 10, 261-280. https://doi.org/10.1016/j.uclim.2013.10.002

Kotthaus, S., O'Connor, E., Münkel, C., Charlton-Perez, C., Haeffelin, M., Gabey, A.M., Grimmond, C.S.B., 2016. Recommendations for processing atmospheric attenuated backscatter profiles from Vaisala CL31 ceilometers. Atmos. Meas. Tech. 9, 3769-3791. https://doi.org/10.5194/amt-9-3769-2016

Kucbel, M., Corsaro, A., Švédová, B., Raclavská, H., Raclavský, K., Juchelková, D., 2017. Temporal and seasonal variations of black carbon in a highly polluted European city: Apportionment of potential sources and the effect of meteorological conditions. J. Environ. Manage. 203, 1178-1189. https://doi.org/10.1016/j.jenvman.2017.05.038

Li, J., Liu, X., Yuan, L., Yin, Y., Li, Z., Li, P., Ren, G., Jin, L., Li, R., Dong, Z., Li, Y., Yang, J., 2015. Vertical distribution of aerosol optical properties based on aircraft measurements over the Loess Plateau in China. J. Environ. Sci. 34, 44-56. https://doi.org/10.1016/j.jes.2015.01.021

Liu, D., Allan, J.D., Young, D.E., Coe, H., Beddows, D., Fleming, Z.L., Flynn, M.J., Gallagher, M.W., Harrison, R.M., Lee, J., Prevot, A.S.H., Taylor, J.W., Yin, J., Williams, P.I., Zotter, P., 2014. Size distribution, mixing state and source apportionment of black carbon aerosol in London during winter time. Atmos. Chem. Phys. 14, 1006110084. https://doi.org/10.5194/acp-14-10061-2014

Liu, Y., Daum, P.H., 2008. Relationship of refractive index to mass density and self-consistency of mixing rules for multicomponent mixtures like ambient aerosols. J. Aerosol Sci. 39, 974-986. https://doi.org/10.1016/j.jaerosci.2008.06.006

Lopez, P., 2002. Implementation and validation of a new prognostic large-scale cloud and precipitation scheme for climate and data-assimilation purposes. Q. J. R. Meteorol. Soc. 128, 229-257. https://doi.org/10.1256/00359000260498879

Lu, C.H., Da Silva, A., Wang, J., Moorthi, S., Chin, M., Colarco, P., Tang, Y., Bhattacharjee, P.S., Chen, S.P., Chuang, H.Y., Juang, H.M.H., McQueen, J., Iredell, M., 2016. The implementation of NEMS GFS Aerosol Component (NGAC) Version 1.0 for global dust forecasting at NOAA/NCEP. Geosci. Model Dev. 9, $1905-1919$. https://doi.org/10.5194/gmd-9-1905-2016

Lufft, 2016. Cloud Height Sensor CHM 15k User Manual. Fellbach, Germany.

Manners, J., Edwards, J.M., Hill, P., Thelen, J., 2015. SOCRATES Technical Guide Suite Of Community Radiative Transfer codes based on Edwards and Slingo.

Marley, N.A., Gaffney, J.S., 2006. Introduction to Urban Aerosols and Their Impacts. ChemInform 37, 1-22. https://doi.org/10.1002/chin.200650274 
Warren E, C Charlton-Perez, S Kotthaus, H Lean, S Ballard, E Hopkin, S Grimmond 2018 Evaluation of forward-modelled attenuated backscatter using an urban ceilometer network in London under clear-sky conditions Atmospheric Environment https://doi.org/10.1016/j.atmosenv.2018.04.045

Martucci, G., Milroy, C., O’Dowd, C.D., 2010. Detection of Cloud-Base Height Using Jenoptik CHM15K and Vaisala CL31 Ceilometers. J. Atmos. Ocean. Technol. 27, 305-318. https://doi.org/10.1175/2009JTECHA1326.1

McKendry, I.G., van der Kamp, D., Strawbridge, K.B., Christen, A., Crawford, B., 2009. Simultaneous observations of boundary-layer aerosol layers with CL31 ceilometer and 1064/532 nm lidar. Atmos. Environ. 43, 5847-5852. https://doi.org/10.1016/j.atmosenv.2009.07.063

Mittal, L., Baker, T., Fuller, G., 2016. London Air Quality Network Summary Report 2014. Kings College London, London, UK.

Morcrette, J.-J., Boucher, O., Jones, L., Salmond, D., Bechtold, P., Beljaars, A., Benedetti, A., Bonet, A., Kaiser, J.W., Razinger, M., Schulz, M., Serrar, S., Simmons, A.J., Sofiev, M., Suttie, M., Tompkins, A.M., Untch, A., 2009. Aerosol analysis and forecast in the European Centre for Medium-Range Weather Forecasts Integrated Forecast System: Forward modeling. J. Geophys. Res. 114, D06206. https://doi.org/10.1029/2008JD011235

Morcrette, J.J., Beljaars, A., Benedetti, A., Jones, L., Boucher, O., 2008. Sea-salt and dust aerosols in the ECMWF IFS model. Geophys. Res. Lett. 35, 1-5. https://doi.org/10.1029/2008GL036041

Müller, D., Ansmann, A., Mattis, I., Tesche, M., Wandinger, U., Althausen, D., Pisani, G., 2007. Aerosol-type-dependent lidar ratios observed with Raman lidar. J. Geophys. Res. Atmos. 112, 1-11. https://doi.org/10.1029/2006JD008292

Münkel, C., Eresmaa, N., Räsänen, J., Karppinen, A., 2007. Retrieval of mixing height and dust concentration with lidar ceilometer. Boundary-Layer Meteorol. 124, 117-128. https://doi.org/10.1007/s10546-006-9103-3

Neal, L., 2016. Air Quality Emissions Data. Met Office, Exeter, UK.

O'Connor, E.J., Illingworth, A.J., Hogan, R.J., 2004. A Technique for Autocalibration of Cloud Lidar. Am. Meteorol. Soc. 21, 777-786. https://doi.org/10.1175/15200426(2004)021<0777:ATFAOC>2.0.CO;2

Pappalardo, G., Amodeo, A., Apituley, A., Comeron, A., Freudenthaler, V., Linné, H., Ansmann, A., Bösenberg, J., D’Amico, G., Mattis, I., Mona, L., Wandinger, U., Amiridis, V., Alados-Arboledas, L., Nicolae, D., Wiegner, M., 2014. EARLINET towards an advanced sustainable European aerosol lidar network. Atmos. Meas. Tech. 7, 23892409. https://doi.org/10.5194/amt-7-2389-2014

Poltera, Y., Martucci, G., Collaud Coen, M., Hervo, M., Emmenegger, L., Henne, S., Brunner, D., Haefele, A., 2017. PathfinderTURB: an automatic boundary layer algorithm. Development, validation and application to study the impact on in-situ measurements at the Jungfraujoch. Atmos. Chem. Phys. Discuss. 17, 10051-10070. https://doi.org/10.5194/acp-2016-962

Porson, A., Clark, P.A., Harman, I.N., Best, M.J., Belcher, S.E., 2010. Implementation of a new urban energy budget scheme in the MetUM. Part I: Description and idea lized simulations. Q. J. R. Meteorol. Soc. 136, 1514-1529. https://doi.org/10.1002/qj.668

Povey, A.C., Grainger, R.G., Peters, D.M., Agnew, J.L., 2014. Retrieval of aerosol backscatter, extinction, and lidar ratio from Raman lidar with optimal estimation. Atmos. Meas. Tech. 7, 757-776. https://doi.org/10.5194/amt-7-757-2014

Rodriguez, S., Van Dingenen, R., Putaud, J.-P., Dell'Acqua, A., Querol, X., Alastuey, A., Chenery, S., K.-F., H., Harrison, R., Tardivo, R., Scarnato, B., Gemelli, V., 2007. and Physics A study on the relationship between mass concentrations, chemistry and number size distribution of urban fine aerosols in Milan, Barcelona and London 2217-2232.

Sabbagh-Kupelwieser, N., Horvath, H., Szymanski, W.W., 2010. Urban aerosol studies of PM1 size fraction with reference to ambient conditions and visibility. Aerosol Air Qual. Res. 10, 425-432. https://doi.org/10.4209/aaqr.2010.02.0009

Savage, N.H., Agnew, P., Davis, L.S., Ordonez, C., Thorpe, R., Johnson, C.E., O'Connor, F.M., Dalvi, M., 2013. Air quality modelling using the Met Office Unified Model (AQUM OS24-26): model description and initial evaluation. Geosci. Model Dev. 6, 353-372. https://doi.org/10.5194/gmd-6-353-2013

Schafer, K., Emeis, S., Schrader, S., Torok, S., Alfoldy, B., Osan, J., Pitz, M., Munkel, C., Cyrys, J., Peters, a, Sarigian nis, D., Suppan, P., 2011. A measurement based analysis of the spatial distribution, temporal variation and chemical composition of particulate matter in Munich and Augsburg. Meteorol. Zeitschrift 20, $47-57$. https://doi.org/10.1127/0941-2948/2011/0498

Schäfer, K., Wagner, P., Emeis, S., Jahn, C., Münkel, C., Suppan, P., Ecology, L., Gmbh, V., 2012. Mixing layer height and air pollution levels in urban area. Proc. SPIE 8534, 110. https://doi.org/10.1117/12.974328

Seinfeld, J.H., Pandis, S.N., 2016. Atmospheric Chemistry and Physics: From Air Pollution to Climate Change. Wiley, Haboken

Sharma, S., Vaishnav, R., Shukla, M. V., Kumar, P., Kumar, P., Thapliyal, P.K., Lal, S., Acharya, Y.B., 2015. Evaluation of cloud base height measurements from ceilometer CL31 and MODIS satellite over Ahmedabad, India. Atmos. Meas. Tech. Discuss. 8, 11729-11752. https://doi.org/10.5194/amtd-8-11729-2015

Stull, R.B., 1988. An Introduction to Boundary Layer Meteorology. Kluwer Academic Publishers, Dordlecht, Netherlands.

Sugimoto, N., Matsui, I., Shimizu, A., Nishizawa, T., Hara, Y., Xie, C., Uno, I., Yumimoto, K., Wang, Z., Yoon, S.-C., 2008. Lidar network observations of tropospheric aerosols, in: Singh, U.N., Asai, K., Jayaraman, A. (Eds.), Lidar Remote Sensing for Environmental Monitoring IX. Noumea, New Caledonia. https://doi.org/10.1117/12.806540

Tang, Y., Lean, H.W., Bornemann, J., 2013. The benefits of the Met Office variable resolution NWP model for forecasting convection. Meteorol. Appl. 20, 417-426. https://doi.org/10.1002/met.1300

Toon, O.B., Pollack, J.B., Khare, B.N., 1976. The optical constants of several atmospheric aerosol species: Ammonium sulfate, aluminum oxide, and sodium chloride. J. Geophys. Res. 81, 5733-5748. https://doi.org/10.1029/JC081i033p05733

Varutbangkul, V., Brechtel, F.J., Bahreini, R., Ng, N.L., Keywood, M.D., Kroll, J.H., Flagan, R.C., Seinfeld, J.H., Lee, a., Goldstein, a. H., 2006. Hygroscopicity of secondary organic aerosols formed by oxidation of cycloalkenes, monoterpenes, sesquiterpenes, and related compounds. Atmos. Chem. Phys. Discuss. 6, $1121-1177$. https://doi.org/10.5194/acpd-6-1121-2006

Wagner, P., Schäfer, K., 2015. Influence of mixing layer height on air pollutant concentrations in an urban street canyon. Urban Clim. 1-13. https://doi.org/10.1016/j.uclim.2015.11.001

Wang, W., Gong, W., Mao, F., Pan, Z., Liu, B., 2016. Measurement and study of lidar ratio by using a Raman lidar in central China. Int. J. Environ. Res. Public Health 13. https://doi.org/10.3390/ijerph13050508

Weast, R.C. (Ed.), 1977. CRC Handbook of Chemistry and Physics, 58th Edition, 58th Ed. ed. CRC Press.

Wiegner, M., Gasteiger, J., 2015. Correction of water vapor absorption for aerosol remote sensing with ceilometers. Atmos. Meas. Tech. 8, 3971-3984. https://doi.org/10.5194/amt-8-3971-2015

Wiegner, M., Madonna, F., Binietoglou, I., Forkel, R., Gasteiger, J., Geiß, A., Pappalardo, G., Schäfer, K., Thomas, W., 2014. What is the benefit of ceilometers for aerosol remote sensing? An answer from EARLINET. Atmos. Meas. Tech. 7, 1979-1997. https://doi.org/10.5194/amt-7-1979-2014

Willén, U., Crewell, S., Baltink, H.K., Sievers, O., 2005. Assessing model predicted vertical cloud structure and cloud overlap with radar and lidar ceilometer observations for the Baltex Bridge Campaign of CLIWA-NET. Atmos. Res. 75, 227-255. https://doi.org/10.1016/j.atmosres.2004.12.008

Wright, B., 1997. A New Visibility Analysis / Forecast System for Nimrod, Forecasting Research Technical Report No. 222.

Xing, Y.F., Xu, Y.H., Shi, M.H., Lian, Y.X., 2016. The impact of PM2.5 on the human respiratory system. J. Thorac. Dis. 8, E69-E74. https://doi.org/10.3978/j.issn.20721439.2016.01.19

Yin, H., Pizzol, M., Xu, L., 2017. External costs of PM2.5 pollution in Beijing, China: Uncertainty analysis of multiple health impacts and costs. Environ. Pollut. $226,356-369$. https://doi.org/10.1016/j.envpol.2017.02.029

You, W., Zang, Z., Zhang, L., Zhang, M., Pan, X., Li, Y., 2016. A nonlinear model for estimating ground-level PM10 concentration in Xi'an using MODIS aerosol optical depth retrieval. Atmos. Res. 168, 169-179. https://doi.org/10.1016/j.atmosres.2015.09.008

Young, D.E., Allan, J.D., Williams, P.I., Green, D.C., Flynn, M.J., Harrison, R.M., Yin, J., Gallagher, M.W., Coe, H., 2015. Investigating the annual behaviour of submicron secondary inorganic and organic aerosols in London. Atmos. Chem. Phys. 15, 6351-6366. https://doi.org/10.5194/acp-15-6351-2015

Zéphoris, M., Holin, H., Lavie, F., Cenac, N., Cluzeau, M., Delas, O., Eideliman, F., Gagneux, J., Gander, A., Thibord, C., 2005. Ceilometer observations of aerosol layer structure above the Petit Lubéron during ESCOMPTE's IOP 2. Atmos. Res. 74, 581-595. https://doi.org/10.1016/j.atmosres.2004.06.014

\section{Notation and abbreviations}

aerFO

Aerosol forward operator

ALC Automatic lidars and ceilometers

asl Above sea level

agl Above ground level 


\begin{tabular}{|c|c|}
\hline$C_{a b s, a e r}$ & Particle mass absorption \\
\hline$C_{a b s, w v}$ & Water vapour specific absorption \\
\hline$C_{e x t, a e r}$ & Particle mass extinction \\
\hline$C_{\text {scat,aer }}$ & Particle mass scattering \\
\hline CALIOP & Cloud-Aerosol Lidar with Orthogonal Polarization \\
\hline CALIPSO & Cloud-Aerosol Lidar and Infrared Pathfinder Satellite Observations \\
\hline DA & Data assimilation \\
\hline$d_{g}$ & Geometric standard deviation \\
\hline ECMWF & European Centre for Medium-Range Weather Forecasts \\
\hline$f_{\text {ext,rh }}$ & Extinction enhancement factor \\
\hline FO & Forward operator \\
\hline FWHM & Full width half maximum \\
\hline IFS & Integrated Forecasting System \\
\hline JULES & Joint UK Land Environment Simulator \\
\hline LAQN & London Air Quality Network \\
\hline LBLRTM & Line-by-line radiative transfer model \\
\hline LUT & Look up table \\
\hline LUMO & London Urban Meteorological Observatory \\
\hline$m$ & Aerosol mass mixing ratio \\
\hline$m_{0}$ & 'Standard' mass mixing ratio \\
\hline$m_{M U R K}$ & MURK aerosol mass mixing ratio \\
\hline MO & Met Office \\
\hline MORUSES & Met Office - Reading Urban Surface Exchange Scheme \\
\hline$N_{0}$ & Total particle number concentration \\
\hline $\mathrm{OC}$ & Organic carbon \\
\hline$n_{i}$ & Partial refractive index of the bulk aerosol \\
\hline$n_{\text {MURK }}$ & Refractive index for the bulk aerosol \\
\hline NWP & Numerical weather prediction \\
\hline$p$ & Scaling power \\
\hline$p_{\text {air }}$ & Air pressure \\
\hline$q$ & Specific humidity \\
\hline$Q_{e x t}$ & Particle extinction efficiency \\
\hline$Q_{\text {ext,dry }}$ & Dry particle extinction efficiency \\
\hline$Q_{H}$ & Sensible heat flux \\
\hline$Q_{H, m}$ & Modelled sensible heat flux \\
\hline$Q_{H, o}$ & Observed sensible heat flux \\
\hline$R$ & Spearman correlation coefficient \\
\hline$r_{0}$ & 'Standard' mass particle radius \\
\hline$r_{g}$ & Geometric mass mean radius \\
\hline$R H$ & Relative humidity \\
\hline$r_{m d}$ & Dry mean particle radius \\
\hline$r_{v}$ & Water vapour mixing ratio \\
\hline$S$ & Lidar ratio \\
\hline SNR & Signal-to-noise ratio \\
\hline$T$ & Two-way transmission \\
\hline$T_{\text {air }}$ & Air temperature \\
\hline UKV & UK Variable Resolution model \\
\hline$v_{i}$ & Volume fractional contribution \\
\hline WS & Weather station \\
\hline$z$ & Height \\
\hline$\beta$ & Backscatter \\
\hline$\beta_{m \text {, unatt }}$ & Forward modelled unattenuated backscatter \\
\hline$\beta_{m}$ & Forward modelled attenuated backscatter \\
\hline$\beta_{o}$ & Observed attenuated backscatter \\
\hline$\eta$ & Proportionality constant \\
\hline$\lambda$ & Wavelength \\
\hline$\rho_{\text {air }}$ & Air density \\
\hline
\end{tabular}




$\begin{array}{ll}\sigma_{e x t} & \text { Extinction coefficient } \\ \sigma_{\text {ext,aer }} & \text { Particle extinction coefficient } \\ \sigma_{\text {ext,wv }} & \text { Water vapour extinction coefficient } \\ \tau & \text { Optical depth }\end{array}$

\section{Appendix 1. MURK aerosol and visibility scheme}

MURK is calculated from UKV ancillaries using (Neal, 2016):

$$
m=0.33 * S O_{2}+0.15 * N O_{2}+0.34 * V O C
$$

where $\mathrm{SO}_{2}$ is sulphur dioxide, $\mathrm{NO}_{2}$ is nitrogen dioxide and $\mathrm{VOC}$ are volatile organic compounds. Eqn A2.1 converts these compounds into ammonium sulphate, ammonium nitrate and organic carbon from the species emissions inventories

The MURK aerosol has a simple flux term as a boundary condition to help distinguish European from Atlantic emissions, as well as small background terms to represent distant sources which are designed to decay exponentially with height (eqn 6 in Clark et al., 2008). It also adds a source term to cells over the ocean to represent sea salt. Wet and dry deposition are parameterised. MURK has a simple monthly variation with a smooth transition between months (Neal, 2016), as well as a sinusoidal diurnal cycle that peaks at 12 UTC (personal communication, Clark, 09 August 2016). On 3 February 2015, updates were made to the emission ancillaries to take advantage of more recent emission data (internal MO communication). This included using: NAEI (DEFRA, 2016), ENTEC and EMEP (Neal, 2016) datasets. In the MO UKV, emissions are partially constrained using data assimilation of visibility observations. However, this has not always led to an improvement in the forecast of visibility, i.e. if visibility is underestimated and model $R H$ is low, the MURK emissions are raised to unrealistically high levels in order to correct the visibility (Claxton, 2013).

The visibility parameterisation was originally developed assuming the aerosol was comprised entirely of ammonium sulphate (Clark et al., 2008) as the inventory used from the mid 1990's was based on sulphur dioxide emission data (Wright, 1997). In order to assess the parameterisation an aircraft observation campaign was undertaken (2006-2007) (Haywood et al., 2008), which obtained number concentration distributions and found the typical aerosol composition in the UK included sulphates, nitrates and organic carbon. Several parameters of the MURK scheme were modified accordingly, including the standard dry radius and number concentration.

\section{Supplementary Material}

Warren E, C Charlton-Perez, S Kotthaus, H Lean, S Ballard, E Hopkin, S Grimmond Evaluation of forward-modelled attenuated backscatter using an urban ceilometer network in London under clear-sky conditions

\section{Variation of the extinction enhancement factor with respect to wavelength around the central wavelength of a Vaisala CL31}

For each wavelength the ratio of $f_{\text {ext }, r h}$ to its values at the nominal centre wavelength $(\lambda=905 \mathrm{~nm})$ are determined for three MURK constituents and the bulk aerosol (Figure S.1). The relative differences are generally $<2 \%$ but non-linear with relative humidity changes. However, these are mostly artefacts from using LUTs from the radiation code, with discontinuities in the parameterisations with $R H$ (section 2). Thus, the impact of wavelength variation between individual sensors of the same design can be treated as negligible. 


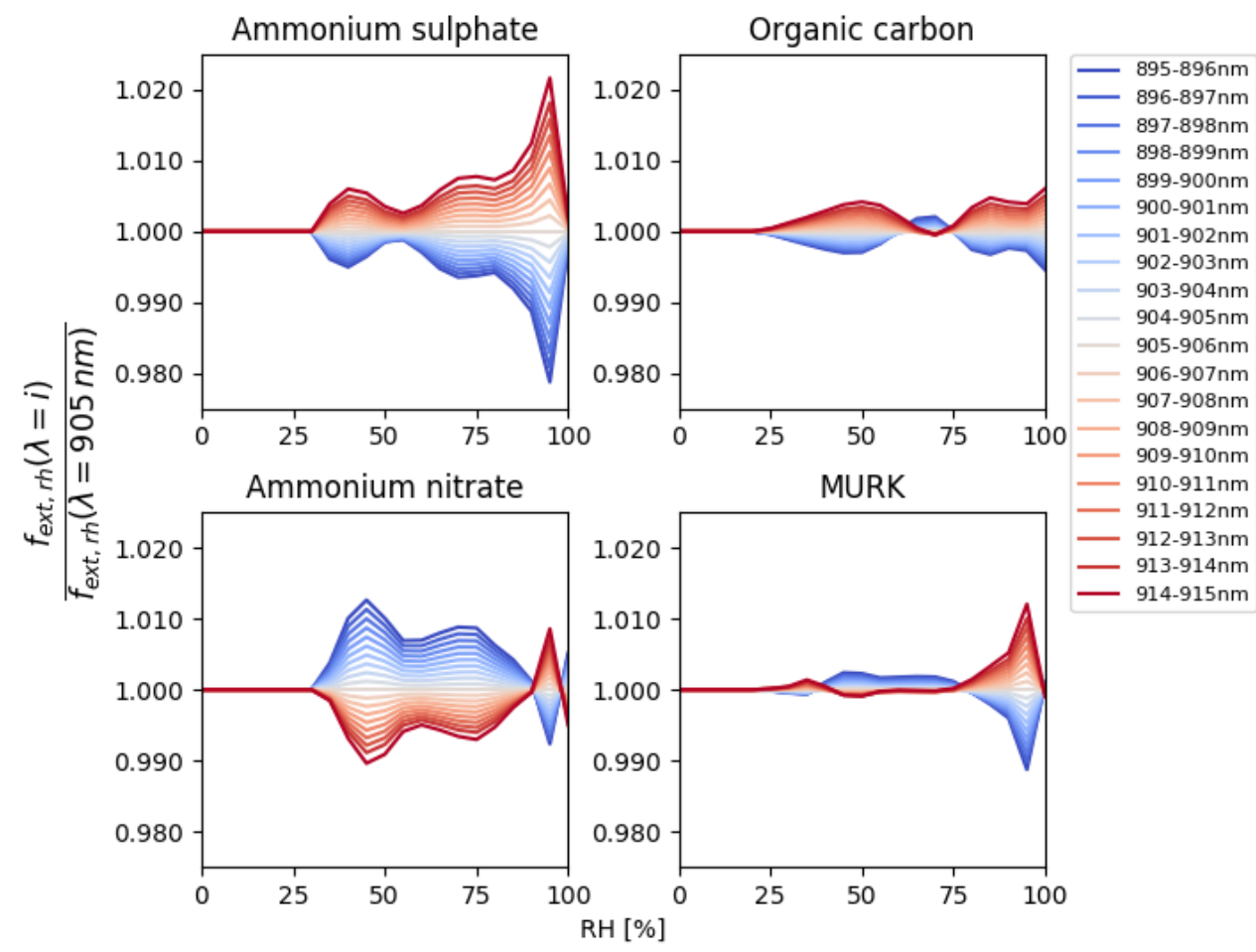

Figure S.1: Extinction enhancement coefficient $\left(f_{\text {ext, } r h}\right)$ variation with RH for different wavelengths (colour) normalized by $905 \mathrm{~nm}$ results for MURK and its three constituents. Wavelength ranges from 895 (light green) to 915 (dark blue) nm, with a bandwidth of 1 $n m$.

Variation in ratio of modelled to observed attenuated backscatter with respect to modelled relative humidity and aerosol.

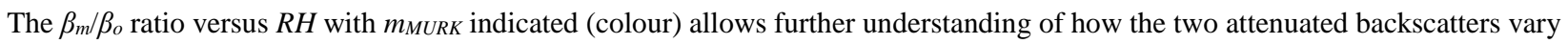
more generally (Figure $\mathrm{S} 2$ ). $\beta_{m} / \beta_{o}$ is often low (mean ratio $=0.53$ at MR), with the smallest values typically occurring when $m_{M U R K}$ was relatively low $\left(<\sim 30 \mu \mathrm{g} \mathrm{kg}^{-1}\right)$. Lower $m_{M U R K}$ will lead to smaller mean dry radii $\left(r_{m d}\right)$ and mean number concentration $(N)$ estimates, which generates a lower extinction coefficient and $\beta_{m}$. Consequently, this also limits the effect of $R H$ as it is parameterised as an extinction enhancement; hence, $\beta_{m} / \beta_{o}$ with relatively low $m_{M U R K}$ values do not increase greatly with increasing $R H$ (Figure 8 ). $\beta_{m} / \beta_{o}$ increases with larger values of $m_{M U R K}\left(>\sim 30 \mu \mathrm{g} \mathrm{kg}^{-1}\right)$, which reflects the larger estimates of $r_{m d}$ and $N$ values and the relatively larger impact of extinction enhancement from $R H$. In addition, the increased sensitivity to $R H$ at higher $m_{M U R K}$ leads to an increased scatter that reflects the increased impact of $R H$ error between modelled and observed $R H$.

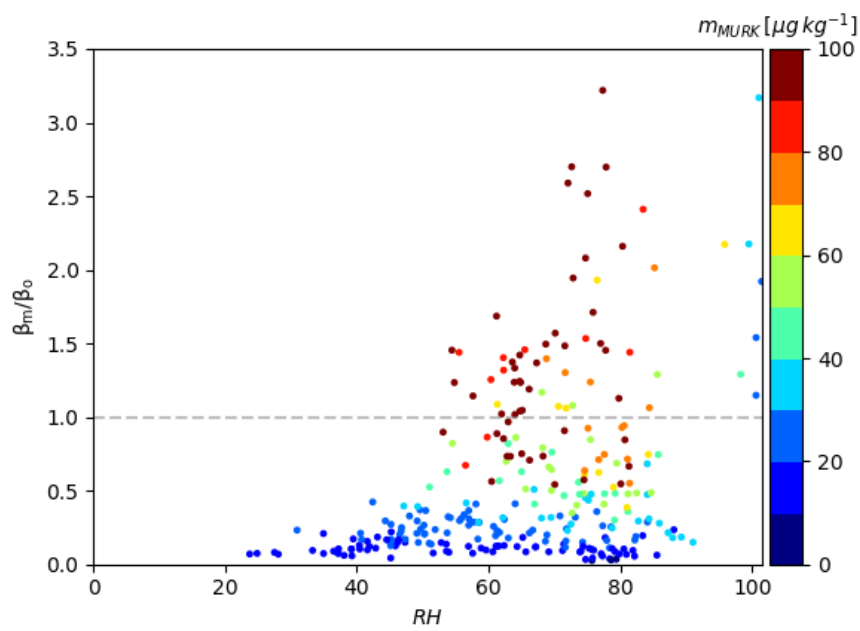

Figure S 2: Ratio of modelled attenuated backscatter to observed attenuated backscatter $\left(\beta_{m} / \beta_{o}\right)$ verses UKV relative humidity $(R H)$, with the UKV aerosol ( $m$, colour) indicated, for MR. $\beta_{m}$ values for $21.7 \mathrm{~m}$ agl, which corresponds to the ALC's second range gate. $m$ and $R H$ for $5 \mathrm{~m}$ agl. Nearest time of $\beta_{0}$ vertical profile is compared to each $\beta_{m}$ profile (261 profiles, from 12 days, Table 3). 